\title{
Diurnal variation in the coupling of photosynthetic electron transport and carbon fixation in iron-limited phytoplankton in the NE subarctic Pacific
}

\author{
Nina Schuback $^{1}$, Mirkko Flecken ${ }^{2}$, Maria T. Maldonado ${ }^{1}$, and Philippe D. Tortell ${ }^{1,3}$ \\ ${ }^{1}$ Departement of Earth, Ocean and Atmospheric Sciences, University of British Columbia, Vancouver, BC, Canada \\ ${ }^{2}$ RWTH Aachen University, Aachen, Germany \\ ${ }^{3}$ Department of Botany, University of British Columbia, Vancouver, BC, Canada
}

Correspondence to: Nina Schuback (nschuback@eos.ubc.ca)

Received: 30 September 2015 - Published in Biogeosciences Discuss.: 19 October 2015

Revised: 27 January 2016 - Accepted: 7 February 2016 - Published: 23 February 2016

\begin{abstract}
Active chlorophyll $a$ fluorescence approaches, including fast repetition rate fluorometry (FRRF), have the potential to provide estimates of phytoplankton primary productivity at an unprecedented spatial and temporal resolution. FRRF-derived productivity rates are based on estimates of charge separation in reaction center II $\left(E R_{R C I I}\right)$, which must be converted into ecologically relevant units of carbon fixation. Understanding sources of variability in the coupling of ETR $\mathrm{RCII}_{\text {and }}$ carbon fixation provides physiological insight into phytoplankton photosynthesis and is critical for the application of FRRF as a primary productivity measurement tool. In the present study, we simultaneously measured phytoplankton carbon fixation and $\mathrm{ETR}_{\mathrm{RCII}}$ in the iron-limited NE subarctic Pacific over the course of a diurnal cycle. We show that rates of $\mathrm{ETR}_{\mathrm{RCII}}$ are closely tied to the diurnal cycle in light availability, whereas rates of carbon fixation appear to be influenced by endogenous changes in metabolic energy allocation under iron-limited conditions. Unsynchronized diurnal oscillations of the two rates led to 3.5 -fold changes in the conversion factor between ETR $_{\mathrm{RCII}}$ and carbon fixation $\left(K_{\mathrm{c}} / n_{\mathrm{PSII}}\right)$. Consequently, diurnal variability in phytoplankton carbon fixation cannot be adequately captured with FRRF approaches if a constant conversion factor is applied. Utilizing several auxiliary photophysiological measurements, we observed that a high conversion factor is associated with conditions of excess light and correlates with the increased expression of non-photochemical quenching (NPQ) in the pigment antenna, as derived from FRRF measurements. The observed correlation between NPQ and $K_{\mathrm{c}} / n_{\mathrm{PSII}}$ requires further validation but has the potential
\end{abstract}

to improve estimates of phytoplankton carbon fixation rates from FRRF measurements alone.

\section{Introduction}

Marine phytoplankton account for $\sim 50 \%$ of global carbon fixation (Field et al., 1998) and play a key role in Earth's biogeochemical cycles. Understanding the spatial and temporal patterns in marine primary productivity and its response to environmental variability is thus a central oceanographic research question. Traditionally, rates of phytoplankton primary production have been measured using incubation-based assays, tracing the evolution of oxygen or the assimilation of $\mathrm{CO}_{2}$ (Williams et al., 2008). Over the past 2 decades, biooptical approaches based on measurements of active chlorophyll $a$ fluorescence (ChlF) yields (Kolber and Falkowski, 1993; Schreiber, 2004) have emerged as an attractive alternative, avoiding artifacts related to bottle containment and achieving unparalleled spatial and temporal resolution. The method most prominently applied to measure ChlF yields in field assemblages of marine phytoplankton is fast repetition rate fluorometry (FRRF) (Kolber et al., 1998). ChlF yields, as measured by FRRF, can be used to estimate electron transport in photosystem II $\left(\mathrm{ETR}_{\mathrm{RCII}}, \mathrm{mol} \mathrm{e}^{-} \mathrm{mol} \mathrm{RCII}^{-1} \mathrm{~s}^{-1}\right)$, and these rates can be converted to carbon units based on theoretical calculations. However, empirical comparison of

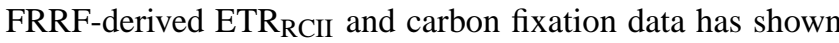
that the derived conversion factor varies significantly with changes in the physiology and taxonomic composition of 
phytoplankton assemblages (Suggett et al., 2010; Lawrenz et al., 2013).

The conversion factor linking $\mathrm{ETR}_{\mathrm{RCII}}$ and carbon fixation consists of two parameters, the amount of chlorophyll $a$ per number of functional PSII reaction centers $\left(1 / n_{\mathrm{PSII}}\right.$; mol chl $a$ mol RCII $\left.{ }^{-1}\right)$ and the electron requirement for carbon fixation $\left(K_{\mathrm{c}}\right.$; $\mathrm{mol}^{-} \mathrm{mol} \mathrm{C}^{-1}$; note that in most previous studies, this latter parameter has been denoted as $\left.\Phi_{\mathrm{e}: \mathrm{C}}\right)$. Plasticity in both $1 / n_{\text {PSII }}$ and $K_{\mathrm{c}}$ can be observed at the physiological and taxonomic level and is ultimately a function of given environmental conditions.

Phytoplankton photosynthesis and downstream metabolic processes exhibit great plasticity and interconnectivity, allowing rapid responses and optimized growth under fluctuating light and nutrient conditions. This physiological regulation influences the coupling between ETR $_{\mathrm{RCII}}$ and carbon fixation. For example, energy (ATP) and reducing power (NADPH) from the photosynthetic light reaction can be used directly for the reduction or assimilation of limiting nutrients, rather than for carbon fixation (e.g., Laws, 1991; Myers, 1980), resulting in an increased conversion factor $K_{\mathrm{c}} / n_{\text {PSII }}$. Furthermore, $K_{\mathrm{c}} / n_{\text {PSII }}$ has been shown to increase under excess light conditions (Cheah et al., 2011; Corno et al., 2006; Fujiki et al., 2007; Goto et al., 2008; Kaiblinger and Dokulil, 2006; Raateoja, 2004), when the rate of charge separation in RCII can outpace the rate of electron transport along the photosynthetic electron transport chain (ETC). In order to alleviate the ensuing "back pressure", which can lead to, e.g., singlet oxygen formation and photoinhibition, photosynthetic organisms evolved a number of "safety valves" along the ETC (e.g., Niyogi, 2000). Activation of these alternative electron pathways diverts absorbed energy away from the carbon fixation, thus increasing the conversion factor $K_{\mathrm{c}} / n_{\text {PSII }}$. In a previous study, we showed that low iron concentrations enhanced the effect of excess light, further increasing the conversion factor $K_{\mathrm{c}} / n_{\mathrm{PSII}}$ (Schuback et al., 2015).

Given the well-established effect of excess light on the coupling of photosynthetic electron transport and carbon fixation, it is likely that the two rates decouple over the course of a diurnal cycle if excess irradiance is encountered at noon. However, to our knowledge, there are no direct experimental studies of the diurnal changes in the coupling of ETR $\mathrm{RCII}_{\mathrm{R}}$ and carbon fixation in marine phytoplankton.

In the present study we simultaneously measured rates of ${ }^{14} \mathrm{C}$ uptake and $\mathrm{ETR}_{\mathrm{RCII}}$ in iron-limited phytoplankton assemblages in the NE subarctic Pacific over the course of a $24 \mathrm{~h}$ diurnal cycle. Our results show that the conversion factor $K_{\mathrm{c}} / n_{\text {PSII }}$, derived for in situ irradiances at $5 \mathrm{~m}$ depth, varied significantly (by a factor of 3.4) over the diurnal cycle, with most of the variability attributable to changes in $K_{\mathrm{c}}$. Unless both carbon fixation and ETR $\mathrm{RCII}_{\text {are measured and }}$ integrated over a whole diurnal cycle (e.g., Suggett et al., 2006), diurnal variability in $K_{\mathrm{c}} / n_{\text {PSII }}$ should thus be considered, along with phytoplankton taxonomy and nutrient sta- tus (Lawrenz et al., 2013), when deriving regional conversion factors between ETR $_{\mathrm{RCII}}$ and carbon fixation. Building on previously published results (Schuback et al., 2015), we show that the magnitude and variability of $K_{\mathrm{c}} / n_{\mathrm{PSII}}$ can be correlated to FRRF-based measurements of nonphotochemical quenching (NPQNSV).

\section{Methods}

\subsection{Study site and water column hydrography}

Field sampling was conducted on board the CCGS John P. Tully on 17 and 18 June 2014. During the sampling period, the research vessel stayed within $10 \mathrm{~km}$ of Ocean Station Papa (OSP), located in iron-limited waters of the NE subarctic Pacific $\left(50^{\circ} \mathrm{N}, 145^{\circ} \mathrm{W}\right.$; https://www.waterproperties. ca/linep/). We acknowledge that our sampling approach is not truly Lagrangian, and some variability in nutritional status and taxonomic composition of phytoplankton assemblage could have occurred due to water mass advection. However, we expect that surface hydrography and phytoplankton characteristics are sufficiently homogeneous in this oceanic region, such that minor water mass advection would not have significantly influenced primary productivity or photophysiological parameters measured over the diurnal cycle.

During our occupation of OSP, we conducted five conductivity-temperature-depth (CTD) casts (three casts during the $24 \mathrm{~h}$ diurnal experiment and one each before and after the diurnal sampling) to characterize variability in temperature and salinity depth profiles, from which we derived seawater density using the Gibbs Seawater (GSW) toolbox in MATLAB (McDougall and Barker, 2011). Mixed layer depth (MLD) was calculated from a density difference criterion $\left(\Delta \sigma=0.05 \mathrm{~kg} \mathrm{~m}^{-3}\right)$. The depth profile of photosynthetically available radiation (PAR; $400-700 \mathrm{~nm}, \mu$ mol quantam ${ }^{-2} \mathrm{~s}^{-1}$ ) through the upper $100 \mathrm{~m}$ of the water column was obtained using a PAR sensor (Biospherical QSP-400) mounted on the rosette during one of the CTD casts (12:30 local time (LT)). The optical extinction coefficient, $k_{\mathrm{d}}\left(\mathrm{m}^{-1}\right)$, was calculated as

$k_{\mathrm{d}}=\left(\ln E_{0}-\ln E_{z}\right) / z$,

where $E_{0}$ is surface irradiance and $E_{z}$ is irradiance at depth $z$ $(\mathrm{m})$. Surface PAR $\left(E_{0}^{+}\right)$was continuously logged $(10 \mathrm{~min}$ intervals) with a LI-1000 down-welling PAR sensor (LI-COR, USA), mounted in a non-shaded position on the ship's superstructure at a height of ca $7 \mathrm{~m}$ above the sea surface. Unfortunately, $3 \mathrm{~h}$ of PAR data (14:00-17:00 LT) were lost due to an instrument malfunction. To fill the data gap, we utilized shortwave solar radiation data from a nearby moored surface buoy, operated by the Ocean Climate Stations (OCS) group at the Pacific Marine Environmental Laboratory of the National Oceanic and Atmospheric Administration (PMEL-NOAA). All mooring data are available from the NOAA OCS web- 
Table 1. Parameters measured at each time point during the diurnal experiment.

\begin{tabular}{lcccccccc}
\hline Time point & 1 & 2 & 3 & 4 & 5 & 6 & 7 & 8 \\
\hline Local time & $03: 00$ & $06: 00$ & $09: 00$ & $12: 00$ & $15: 00$ & $18: 00$ & $21: 00$ & $00: 00$ \\
[chl $a$ ] & $\mathrm{x}$ & $\mathrm{x}$ & $\mathrm{x}$ & $\mathrm{x}$ & $\mathrm{x}$ & $\mathrm{x}$ & $\mathrm{x}$ & $\mathrm{x}$ \\
HPLC & $\mathrm{x}$ & & $\mathrm{x}$ & & $\mathrm{x}$ & & $\mathrm{x}$ & \\
Absorption spectra & $\mathrm{x}$ & $\mathrm{x}$ & $\mathrm{x}$ & $\mathrm{x}$ & $\mathrm{x}$ & $\mathrm{x}$ & $\mathrm{x}$ & $\mathrm{x}$ \\
FRRF measurements & $\mathrm{x}$ & $\mathrm{x}$ & $\mathrm{x}$ & $\mathrm{x}$ & $\mathrm{x}$ & $\mathrm{x}$ & $\mathrm{x}$ & $\mathrm{x}$ \\
${ }^{14}$ C uptake & $\mathrm{x}$ & $\mathrm{x}$ & $\mathrm{x}$ & $\mathrm{x}$ & $\mathrm{x}$ & $\mathrm{x}$ & $\mathrm{x}$ & $\mathrm{x}$ \\
\hline
\end{tabular}

Table 2. Phytoplankton pigments used for the derivation of diagnostic pigment ratios. Pigments identified from HPLC analysis were chlorophyll $c_{3}\left(\mathrm{Chl} c_{3}\right)$, chlorophyll $c_{1} c_{2}\left(\mathrm{Chl} c_{1} c_{2}\right)$, 19-butanoyloxyfucoxanthin (19-BF), fucoxanthin (Fc), 19-hexanoyloxyfucoxanthin (19-HF), 9-cis-neoxanthin (Neo), prasinoxanthin (Prasino), violaxanthin (Viola), diadinoxanthin (Dd), alloxanthin (Allox), diatoxanthin (Dt), lutein, zeaxanthin (Zea), chlorophyll $b(\mathrm{Chl} b)$, chlorophyll $a$ allomer (Chl $a$ allomer), chlorophyll $a+\operatorname{divinyl}$ chlorophyll $a$ (Chl $a)$, chlorophyll $a^{\prime}$ $\left(\right.$ Chl $\left.a^{\prime}\right), \alpha$ carotene ( $\alpha$ carot), and $\beta$ carotene ( $\beta$ carot).

\begin{tabular}{ll}
\hline Pigment group & Pigments \\
\hline Photoprotective carotenoids (PPCs) & $\mathrm{Neo}+\mathrm{Viola}+\mathrm{Dd}+\mathrm{Allox}+\mathrm{Dt}+$ Lutein + Zea $+\beta$ carot \\
Photosynthetic carotenoids (PSCs) & $19-\mathrm{BF}+\mathrm{Fc}+19-\mathrm{HF}+\mathrm{Prasino}+\alpha$ carot \\
Total chlorophyll (Tchl) & $\mathrm{Chl} c_{3}+\mathrm{Chl} c_{1} c_{2}+\mathrm{Chl} b+\mathrm{Chl} a$ allomer $+\mathrm{Chl} a+\mathrm{Chl} a^{\prime}$ \\
Total pigment (TPig) & $\mathrm{PPC}+\mathrm{PSC}+\mathrm{Tchl}$ \\
\hline
\end{tabular}

site (http://www.pmel.noaa.gov/OCS). We aligned the two sets of irradiance data (ship-based and surface mooring) and extrapolated over the $3 \mathrm{~h}$ gap in order to obtain consistent $E_{0}^{+}$for the time span of the diurnal experiment. Surface reflectance was calculated as a function of solar zenith angle following Kirk (2011) using the R package "phytotools" (Silsbe, 2015). Subtracting surface reflectance provides PAR just under the air-ocean interface $\left(E_{0}^{-}\right)$. PAR at $5 \mathrm{~m}$ depth $\left(E_{5 \mathrm{~m}}^{-}\right)$was calculated as $E_{5 \mathrm{~m}}^{-}=E_{0}^{-} \exp ^{\left(k_{\mathrm{d}} \times 5 \mathrm{~m}\right)}$.

Macronutrients $(\mathrm{P}, \mathrm{N}, \mathrm{Si})$ were measured on samples from two CTD rosette casts following the methods outlined in Barwell-Clarke (1996). Additional measurements of surface water $(\sim 5 \mathrm{~m})$ temperature and salinity were derived from the ship's thermosalinograph (TSG) connected to a continuous seawater supply and also from the NOAA mooring.

\subsection{Sample collection}

Seawater samples were collected from the seawater intake system (ca. $5 \mathrm{~m}$ depth) every $3 \mathrm{~h}$ over a $24 \mathrm{~h}$ period and processed immediately for a variety of physiological assays described below. The resulting data set consists of eight time points (TPs). Local sunrise, solar noon, and sunset were at 06:30, 14:40, and 22:50, respectively, resulting in three nighttime TPs (03:00, 23:00, 00:00) and five daytime TPs (06:00, 09:00, 12:00, 15:00, 18:00). Samples taken at each $\mathrm{TP}$ are summarized in Table 1.

\section{3 [chl $a$ ] and high-performance liquid chromatography (HPLC)}

At each TP, duplicate $500 \mathrm{~mL}$ samples for [chl $a$ ] were filtered onto pre-combusted $25 \mathrm{~mm}$ glass fiber filters (Whatman $\mathrm{GF} / \mathrm{F})$ using low vacuum pressure $(<50 \mathrm{~mm} \mathrm{Hg})$, taking care to keep the filters out of direct light. Filters were stored at $-20^{\circ} \mathrm{C}$ and analyzed following the method of Welschmeyer (1994) within 2 weeks of collection. At four TPs (03:00, 09:00, 15:00, 21:00) duplicate 2.2 L samples for pigment analysis were filtered onto pre-combusted $25 \mathrm{~mm}$ $\mathrm{GF} / \mathrm{F}$, as above. Filters were blotted dry with absorbent paper, flash frozen in liquid nitrogen, and stored at $-80^{\circ} \mathrm{C}$ until analysis by reverse-phase high-pressure liquid chromatography (HPLC) following the method of Pinckney (2013). The identified pigments were grouped into photosynthetic carotenoids (PSC), photoprotective carotenoids (PPCs), and total chlorophyll (TChl) as outlined in Table 2. Ratios of these pigment groups were used to assess diurnal changes in the extent of light stress experienced by the whole phytoplankton assemblage. Xanthophyll cycling (XC) pigments of chromophytes (diatoxanthin (Dt) and diadinoxanthin (Dd)) as well as xanthophyll cycling pigments of prasinophytes and chlorophytes (violaxanthin (Viol) and zeaxanthin (Zea)) were assessed with regard to their relative abundance ( $(\mathrm{Dt}+$ $\mathrm{Dd}) / \mathrm{chl} a$ and (Zea $+\mathrm{Viol}) / \operatorname{chl} a$ ) and de-epoxidation state ratios (DES, Dt / (Dt + Dd) and Zea / (Zea + Viol). Furthermore, pigment data were used to estimate the relative abundance of different phytoplankton taxa at our sampling site. CHEMTAX analysis was performed using the averaged pigment concentrations from each TP. Analysis was performed 
essentially as described in Taylor et al. (2013).The initial pigment ratio matrix, specific to North Pacific phytoplankton isolates, was taken from Table 5 in Lee et al. (2011).

\subsection{Absorption spectra}

Absorption spectra of phytoplankton cellular pigments $\left(a_{\text {phy }}(\lambda)\right)$ were determined following the quantitative filter technique (QFT) as described in Mitchell et al. (2002). At each TP, duplicate $1.1 \mathrm{~L}$ samples were filtered onto precombusted $25 \mathrm{~mm}$ GF/F under low vacuum pressure and light, taking care to achieve even sample distribution on the filter. Reference filters were prepared by filtering $1.1 \mathrm{~L}$ of Milli-Q water. Filters were carefully placed into $25 \mathrm{~mm}$ tissue capsules (Fisher), flash frozen in liquid nitrogen and stored at $-80^{\circ} \mathrm{C}$ until analysis within 1 month of the experiment. Sample filters were analyzed on a Cary BIO-100 dualbeam spectrophotometer (Varian) against reference filters as described in Mitchell et al. (2002). Optical density (OD) was measured from 370 to $800 \mathrm{~nm}$ ( $1 \mathrm{~nm}$ resolution) before and after the extraction of pigment with $90 \%$ methanol (Kishino et al., 1985) to determine the OD of the whole particulate sample and the OD of detritus after pigment extraction. Each sample and blank was analyzed in triplicate, to minimize error associated with instrument measurements. The wavelength-specific phytoplankton pigment absorption spectrum $\left(a_{\text {phy }}(\lambda), \mathrm{m}^{-1}\right)$ was calculated as

$a_{\text {phy }}(\lambda)=$

$2.303 \times\left(\mathrm{OD}_{\text {sample }}(\lambda)-\mathrm{OD}_{\text {detrius }}(\lambda)\right) \times \frac{A}{V} \times \beta^{-1}$,

where 2.303 is the conversion of from base-10 to a natural logarithm, $A$ is the particulate retention area of the filter $\left(\mathrm{m}^{2}\right), V$ is the volume filtered $\left(\mathrm{m}^{3}\right)$, and $\beta$ is the path length amplification coefficient (4.5; Röttgers and Gehnke, 2012). To determine chl- $a$-specific absorption spectra $\left(a_{\text {phy }}^{*}(\lambda)\right.$, $\mathrm{m}^{-1} \mathrm{mg} \operatorname{chl} a^{-1}$ ), values were normalized to corresponding [chl $a]$ values. Absorption spectra were used for spectral correction of our rate measurements, as described in detail below.

\subsection{FRRF-derived photophysiological parameters and ETR $_{\text {RCII }}$}

All FRRF measurements were conducted on a bench top FRRF instrument (Soliense Inc.), as described in Schuback et al. (2015). At each TP, background fluorescence blanks were prepared by gently syringe filtering a small amount of sample through a pre-combusted GF/F. We applied a single-turnover (ST) protocol consisting of an excitation sequence (100 flashlets with $1.0 \mu$ s length and $2.5 \mu$ interval, $46200 \mu$ mol quantam ${ }^{-2} \mathrm{~s}^{-1}$ peak power intensity, resulting in a excitation sequence of $250 \mu \mathrm{s}$, providing $\sim 5-10$ quanta per RCII), followed by a relaxation sequence (50 flashlets with $1.0 \mu$ s length and $20 \mu$ s interval). Excitation power was provided by an array of eight LEDs at four wavelengths centered on 445, 470, 505, and $530 \mathrm{~nm}$ (equal intensity from each wavelength, applied simultaneously). We measured steady-state light curves (SSLCs), where each sample was exposed to 10 actinic "background" irradiances from 0 to $1000 \mu \mathrm{mol}$ quanta $\mathrm{m}^{-2} \mathrm{~s}^{-1}$, provided at the same four wavelengths. All ChlF yields and parameters described below were derived by an iterative nonlinear fitting procedure, applying the four-parameter biophysical model of Kolber et al. (1998) to a mean of 20 consecutive ST flashlet sequences using custom software (Z. Kolber). This software accounts for the formation of fluorescence quenching, most likely due to the formation of a P680 triplet, which reduces the maximum fluorescence yield attainable during the ST flash by 3-6\%. Throughout the SSLC, ST flashlet sequences were measured continuously ( $1 \mathrm{~s}$ interval) and the length of each light step was optimized to allow all derived parameters to reach steady state (ca. $3 \mathrm{~min}$ ). ChlF yields and parameters corresponding to each light level were obtained from the mean of the last three acquisitions at each light level. In this way, we derived the fluorescence yields $F_{\mathrm{o}}$ and $F_{\mathrm{m}}$ (in darkregulated state) as well as $F^{\prime}$ and $F^{\prime}$ m (in the light-regulated state for each light level of the SSLC). $F_{\mathrm{o}}^{\prime}$ was calculated as $F^{\prime}{ }_{\mathrm{o}}=F_{\mathrm{o}} /\left(F_{\mathrm{v}} / F_{\mathrm{m}}+F_{\mathrm{o}} / F_{\mathrm{m}}^{\prime}\right)$ (Oxborough and Baker, 1997).

The five fluorescence yields $F_{\mathrm{o}}, F_{\mathrm{m}}, F^{\prime}, F^{\prime}{ }_{\mathrm{m}}$, and $F^{\prime}{ }_{\mathrm{o}}$ were used to calculate ChlF parameters, following Roháček (2002) as described in Schuback et al. (2015). Furthermore, the functional absorption cross section of PSII, $\sigma_{\text {PSII }}\left(\times 10^{-20} \mathrm{~m}^{2} \mathrm{RCII}^{-1}\right)$, was derived from the rate of closure of RCII in the dark-regulated and each light-regulated state (Kolber and Falkowski, 1993; Kolber et al., 1998).We calculated ETR $_{\text {RCII }}$ as

$\mathrm{ETR}_{\mathrm{RCII}}=E \times \sigma_{\mathrm{PSII}}^{\prime} \times \frac{F^{\prime}{ }_{\mathrm{q}}}{F^{\prime}{ }_{\mathrm{v}}} \times \Phi_{\mathrm{RC}} \times 6.022 \times 10^{-3}$,

where $E$ ( $\mu$ mol quanta $\mathrm{m}^{-2} \mathrm{~s}^{-1}$ ) is the actinic irradiance at each light level, $\sigma_{\mathrm{PSII}}^{\prime}\left(\times 10^{-20} \mathrm{~m}^{2} \mathrm{RCII}^{-1}\right)$ is the functional absorption cross section of PSII at each light level, and $F^{\prime}{ }_{\mathrm{q}} / F^{\prime}{ }_{\mathrm{v}}$ is the quantum efficiency of photochemical energy conversion in RCII at a given light intensity. The parameter $F^{\prime}{ }_{\mathrm{q}} / F^{\prime}{ }_{\mathrm{v}}$ can also be interpreted as an estimate of the fraction of RCII in the open state, i.e., the primary stable electron acceptor in the oxidized state (Roháček, 2002). The parameter $\Phi_{\mathrm{RC}}\left(\mathrm{mol} \mathrm{e}^{-}\right.$mol photon $\left.^{-1}\right)$ has the constant value of 1 , given that for each photon absorbed and delivered to RCII, one electron is transferred from $P_{680}$ to $Q_{\mathrm{A}}$ (Kolber and Falkowski, 1993). The number $6.022 \times 10^{-3}$ converts $\mu \mathrm{mol}$ quanta to quanta and $10^{-20} \mathrm{~m}^{2}$ to $\mathrm{m}^{2}$.

We additionally calculated $\mathrm{ETR}_{\mathrm{RCII}}$ using the alternative approach

$\mathrm{ETR}_{\mathrm{RCII}}=E \times \sigma_{\mathrm{PSII}} \times \frac{\left(F_{\mathrm{q}}^{\prime} / F_{\mathrm{m}}^{\prime}\right)}{\left(F_{\mathrm{v}} / F_{\mathrm{m}}\right)} \times \Phi_{\mathrm{RC}} \times 6.022 \times 10^{-3}$.

Both calculations are equivalent, assuming that nonphotochemical quenching processes affecting ChlF can be 
adequately accounted for in either the absorption term (Eq. 3) or the efficiency term (Eq. 4). The difference between $\mathrm{ETR}_{\mathrm{RCII}}$ values calculated in both ways $(n=71)$ was negligible, ranging from 1 to $16 \%$ with a mean coefficient of variance of $6 \%$.

The parameter $\tau(\mathrm{ms})$ is the time constant of reoxidation of the primary stable electron acceptor $Q_{\mathrm{A}}$ and was estimated from the relaxation sequence of the ST protocol. We used values of $\tau$, estimated for the dark-regulated state at each TP, to derive estimates of the rate of $Q_{\mathrm{A}}$ reoxidation $\left(1 / \tau ; \mathrm{ms}^{-1}\right)$. Non-photochemical quenching (NPQ) at each light level was estimated as the so-called normalized SternVolmer quenching coefficient, $\mathrm{NPQ} \mathrm{NSV}_{\mathrm{N}}=\left(F_{\mathrm{m}}^{\prime} / F^{\prime}{ }_{\mathrm{v}}\right)-1=$ $F^{\prime}{ }_{\mathrm{o}} / F^{\prime}{ }_{\mathrm{v}}$ (McKew et al., 2013). This alternative approach to the more common estimate of NPQ $\left(\left(F_{\mathrm{m}}-F_{\mathrm{m}}^{\prime}\right) / F_{\mathrm{m}}^{\prime}\right.$; Bilger and Björkman, 1990) represents the ratio of total nonphotochemical energy dissipation in the light-regulated state to the rate constant of photochemistry (McKew et al., 2013).

\subsection{Carbon fixation}

Rates of carbon fixation were measured as small volume $\mathrm{P}$ vs. E curves in a custom-built photosynthetron as described in Schuback et al. (2015). Briefly, $300 \mathrm{~mL}$ water samples were spiked with $\mathrm{NaH}^{14} \mathrm{CO}_{3}$ (final concentration $0.0185 \mathrm{MBq} \mathrm{mL}^{-1}, 1942.5 \mathrm{MBq} \mathrm{mL}^{-1}$ specific activity) (Perkin-Elmer). All sample manipulations were conducted under low light. Samples were spiked with tracer within 30 min of sampling, mixed gently but thoroughly, and then aliquoted into $20 \mathrm{~mL}$ glass scintillation vials and placed into the photosynthetron. The total ${ }^{14} \mathrm{C}$ activity added was determined from three $1 \mathrm{~mL}$ aliquots of the spiked sample added to $1 \mathrm{~mL}$ of $1 \mathrm{M} \mathrm{NaOH}$. Additionally, three time-zero samples were taken for each curve by filtering $20 \mathrm{~mL}$ immediately after adding the spike. During the incubations, temperature was kept within $1{ }^{\circ} \mathrm{C}$ of in situ temperature by circulating water from a water bath through an aluminum cooling jacket. Each $P$ vs. E curve consisted of 11 light levels spanning intensities from 3 to $600 \mu \mathrm{mol}$ quanta $\mathrm{m}^{-2} \mathrm{~s}^{-1}$. Incubations lasted for $3.5 \mathrm{~h}$ and were ended by gentle filtration onto pre-combusted $25 \mathrm{~mm}$ GF/F filters. Given the length of the incubations and the likely slow growth rate of the iron-limited phytoplankton assemblage sampled, our approach probably reflects a rate closer to net rather than gross primary productivity (e.g., Halsey et al., 2011; Pei and Laws, 2013).

Filters were stored in scintillation vials at $-20^{\circ} \mathrm{C}$ until processing within 1 month of the experiment. During laboratory processing, $500 \mu \mathrm{L}$ of $3 \mathrm{M} \mathrm{HCl}$ was added to each filter and vials were left to degas for $>24 \mathrm{~h}$ to eliminate any inorganic ${ }^{14} \mathrm{C}$ remaining in the samples. Ten milliliters of scintillation cocktail (Scintisafe plus, Fisher) were added to each vial, and vials were then vortexed and left to stand in the dark for $>12 \mathrm{~h}$ before analysis on a liquid scintillation counter (Beckman). Disintegrations per minute (DPM) were derived from scintillation counts using a quench curve pre- pared from commercial ${ }^{14} \mathrm{C}$ standards (Perkin-Elmer). DPM were converted to units of carbon biomass following Knap et al. (1996).

\subsection{Spectral correction and curve fitting}

To account for differences in the spectral distribution of LEDs used in photosynthetron and FRRF instrument, all rates were divided by a spectral correction factor (SCF).

$\mathrm{SCF}=\frac{\sum_{400}^{700} a_{\mathrm{phy}}^{*}(\lambda) E_{\text {in situ }}(\lambda) \sum_{400}^{700} E_{\mathrm{LED}}(\lambda)}{\sum_{400}^{700} a_{\mathrm{phy}}^{*}(\lambda) E_{\mathrm{LED}}(\lambda) \sum_{400}^{700} E_{\text {in situ }}(\lambda)}$,

where $a_{\mathrm{phy}}^{*}(\lambda)\left(\mathrm{m}^{-1}\right)$ is the [chl $a$ ]-specific phytoplankton pigment absorption spectrum determined for each TP as described above, $E_{\mathrm{LED}}$ is the spectral distribution of the LEDs used in photosynthetron or FRRF, and $E_{\text {in situ }}$ is the spectral distribution of sunlight at $5 \mathrm{~m}$ depth. We estimated the in situ spectral distribution of PAR at $5 \mathrm{~m}$ depth following Stomp et al. (2007) as

$E(\lambda, z)=E_{0}(\lambda) \exp \left(-\left[K_{\mathrm{w}}(\lambda)+K_{\mathrm{GT}}(\lambda)+K_{\mathrm{PH}}(\lambda)\right] z\right)$.

Here, $E_{0}(\lambda)$ is the spectral distribution of incident sunlight and $K_{\mathrm{w}}(\lambda)\left(\mathrm{m}^{-1}\right)$ is the absorption by pure water (Pope and Fry, 1997). $K_{\mathrm{GT}}(\lambda)\left(\mathrm{m}^{-1}\right)$ is the absorption by dissolved and particulate organic matter, estimated as $K_{\mathrm{w}}(\lambda)=K_{\mathrm{GT}}(440) \exp (-S(\lambda-440))$, assuming that $K_{\mathrm{GT}}(440)=0.003 \mathrm{~m}^{-1}$, a typical value of clear openocean water (Morel et al., 2007), and $S=0.017 \mathrm{~nm}^{-1}$ (Kirk, $2010)$. Values for $K_{\mathrm{PH}}(\lambda)\left(\mathrm{m}^{-1}\right)$ were taken from the absorption spectra measured using the filter pad technique as described above.

After spectral correction, carbon fixation and $E_{R} R_{R C I I}$ data were plotted against irradiance and fit to the exponential model of Webb et al. (1974) using a nonlinear least squares regression procedure in MATLAB. For the carbon fixation data, an intercept parameter was added to force the regression through the origin and provide a good fit in the linear part of the P vs. E curve (Arrigo et al., 2010; Suggett et al., 2001). For both rates of productivity, we derived the light-saturated maximum rate $P_{\max }\left(P_{\max }-\mathrm{ETR}_{\mathrm{RCII}}\right.$ and $\left.P_{\max }-\mathrm{C}\right)$, the light utilization efficiency $\alpha\left(\alpha-\mathrm{ETR}_{\mathrm{RCII}}\right.$ and $\alpha-\mathrm{C})$, and the light saturation point $E_{\mathrm{k}}=P_{\max } / \alpha$. When photoinhibition was observed at high irradiances, the data points were excluded from the fitting procedure.

\subsection{Derivation of conversion factor}

The conversion factor linking ETR $_{\mathrm{RCII}}$ $\left(\mathrm{mol} \mathrm{e}^{-} \mathrm{mol} \mathrm{RCII}^{-1} \mathrm{~s}^{-1}\right)$ and carbon fixation (molCmolchl $a^{-1} \mathrm{~s}^{-1}$ ) was derived as described in 
Schuback et al. (2015):

$$
\begin{aligned}
& \frac{\operatorname{ETR}_{\mathrm{RCII}}\left(\mathrm{mol} \mathrm{e}^{-} \mathrm{mol} \mathrm{RCII}{ }^{-1} \mathrm{~s}^{-1}\right)}{\text { C-fixation }\left(\mathrm{molCmol} \mathrm{ch} a^{-1} \mathrm{~s}^{-1}\right)}= \\
& K_{\mathrm{c}}\left(\frac{\mathrm{mol} \mathrm{e}}{\operatorname{molC}}\right) \times 1 / n_{\mathrm{PSII}}\left(\frac{\operatorname{molchl} a}{\operatorname{mol} \mathrm{RCII}}\right) .
\end{aligned}
$$

In this approach, the conversion factor between the two rates accounts for changes in chl $a$ functionally associated with each RCII $\left(1 / n_{\mathrm{PSII}}\right.$, molchl $\left.a \mathrm{~mol} \mathrm{RCII}^{-1}\right)$, as well as variability in the number of charge separations in RCII per $\mathrm{CO}_{2}$ assimilated $\left(K_{\mathrm{c}}, \mathrm{mole}^{-} \mathrm{molC}^{-1}\right)$. Reported values for $K_{\mathrm{c}}$ range from 1.15 to $54.2 \mathrm{~mol} \mathrm{e}^{-} \mathrm{mol} \mathrm{C}^{-1}$ (Lawrenz et al., 2013) and 200-950 mol chl $a \mathrm{~mol} \mathrm{RCII}^{-1}$ for $1 / n_{\text {PSII }}$ (Suggett et al., 2010). Consequently, values of $K_{\mathrm{c}} / n_{\text {PSII }}$ could be expected to range from 230$51490 \mathrm{~mol} \mathrm{e}^{-} \mathrm{mol} \mathrm{C}^{-1} \mathrm{~mol} \mathrm{chl} a$ mol RCII ${ }^{-1}$.

Based on the measured light dependence of carbon fixation and $\mathrm{ETR}_{\mathrm{RCII}}$ for each sample, we were able to derive the light dependency of the conversion factor $K_{\mathrm{c}} / n_{\text {PSII }}$ at each TP. Additionally, we used $\alpha$ and $P_{\max }$ values from the ETR $_{\mathrm{RCII}}$ and ${ }^{14} \mathrm{C} \mathrm{P}$ vs. E curves to derive the conversion factor under subsaturating and saturating light conditions, respectively.

\subsection{Relative changes in $1 / n_{\text {PSII }}$}

Combining two unknown variables $\left(K_{\mathrm{c}}\right.$ and $\left.1 / n_{\text {PSII }}\right)$ into one conversion factor, as described above, limits our ability to physiologically interpret observed changes in the coupling of carbon fixation and photosynthetic electron transport. An approach to estimate values of $1 / n_{\text {PSII }}$ directly from FRRF measurements has recently been developed by Oxborough et al. (2012). This approach relies on the assumption that the ratio of the rate constants of photochemistry $\left(k_{\mathrm{p}}\right)$ and fluorescence $\left(k_{\mathrm{f}}\right)$ stays within a narrow range. This assumption is invalidated under conditions of iron limitation, where $k_{\mathrm{p}}$ decreases while $k_{\mathrm{f}}$ increases (e.g., Vassiliev et al., 1995), likely due to the expression of light harvesting complexes that are energetically decoupled from RCII (Behrenfeld and Milligan, 2013; Schrader et al., 2011). Consequently, the approach of Oxborough et al. (2012) cannot be used to compare samples over a range of iron-limiting conditions.

In the current diurnal study, it is likely that the degree of iron limitation experienced by the phytoplankton assemblage stayed relatively constant during our short sampling period, such that $k_{\mathrm{p}} / k_{\mathrm{f}}$ values would have remained within a narrow range. For this reason, we applied a simplified version of the Oxborough et al. (2012) approach to our data, allowing us to estimate relative diurnal changes in $1 / n_{\text {PSII }}$, and, by deduction, $K_{\mathrm{c}}$. In the original approach by Oxborough et al. (2012), changes in of $F_{\mathrm{O}} / \sigma_{\text {PSII }}$, measured in the darkregulated state, are multiplied by an instrument-specific calibration factor $\left(K_{\mathrm{R}}\right)$ to derive absolute values of [RCII]. Lacking this instrument-specific calibration factor $K_{\mathrm{R}}$, we were not able to derive absolute values for [RCII] (and in turn $\left.1 / n_{\text {PSII }}\right)$. However, since $K_{\mathrm{R}}$ is presumed to be constant, we used $F_{\mathrm{o}} / \sigma_{\mathrm{PSII}}$ measured in the dark regulated state at each TP to derive an estimate of relative [RCII] values. These relative [RCII] values were then normalized to [chl $a$ ] to estimate diurnal changes in $1 / n_{\text {PSII }}$, which were, in turn, used to estimate relative diurnal changes in $K_{\mathrm{c}}$ from measurements of $K_{\mathrm{c}} / n_{\text {PSII. }}$

\section{Results}

\subsection{Physical and chemical characteristics of the water column during the experiment}

During the sampling period, the upper water column at OSP was stratified, with a well-defined mixed layer of $33 \pm$ $2 \mathrm{~m}$. As expected for iron-limited waters, excess macronutrients were present in the mixed layer and concentrations did not vary over the course of our sampling (two casts, 03:30 and 12:30LT; $N=9.1 \pm 0.00 \mu \mathrm{mol} \mathrm{L}^{-1}, P=0.98 \pm$ $0.01 \mu \mathrm{mol} \mathrm{L}{ }^{-1}$, and $\left.\mathrm{Si}=14.5 \pm 0.51 \mu \mathrm{mol} \mathrm{L}{ }^{-1}\right)$. Chlorophyll $a$ concentrations were homogeneously distributed throughout the mixed layer $\left(0.26 \pm 0.03 \mathrm{mg} \mathrm{m}^{-3}\right.$; eight depths sampled on one cast at 12:30LT), while temperature was nearly invariant $\left(10.4 \pm 0.07^{\circ} \mathrm{C}\right)$ during our sampling period. The total daily incident PAR dose over the $24 \mathrm{~h}$ period $\left(E_{0}^{+}\right)$was 31.94 mol quanta $\mathrm{m}^{-2}$, with a noon maximum of $1162 \mu$ mol quanta $\mathrm{m}^{-2} \mathrm{~s}^{-1}$. The water column light extinction coefficient, $k_{\mathrm{d}}$, was $0.07 \mathrm{~m}^{-1}$, which is a value typical for the open ocean (Kirk, 2010). The photic zone (defined as the $0.1 \%$ light level) extended below the mixed layer depth at all TPs, apart from the nighttime TP (TPs 1, 7, and 8).

\subsection{Phytoplankton community composition}

CHEMTAX analysis of the pigment data suggested that the phytoplankton assemblage at the sampling location was highly diverse, consisting of approximately $3 \%$ diatoms, $2 \%$ dinoflagellates, $15 \%$ prymnesiophytes, $12 \%$ chlorophytes, $16 \%$ prasinophytes, $14 \%$ cryptophytes, $15 \%$ pelagophytes, and $23 \%$ cyanobacteria.

\subsection{Diurnal changes in rates of carbon fixation and ETRRCII}

Over the course of the diurnal cycle, we observed significant changes in the $\mathrm{P}$ vs. $\mathrm{E}$ curves for carbon fixation and ETR $_{\text {RCII }}$ (Fig. 1). However, the two rates, and their light dependency, did not change in parallel (Fig. 1). As a consequence, we observed significant changes in magnitude and light dependency of the derived conversion factor $K_{\mathrm{c}} / n_{\text {PSII }}$. At all TP, $K_{\mathrm{c}} / n_{\text {PSII }}$ increased with increasing light (Fig. 1). The maximum, light-saturated value of $K_{\mathrm{c}} / n_{\text {PSII }}$ as well as the slope of the light-dependent increase was highest in the afternoon, with maximum $K_{\mathrm{c}} / n_{\text {PSII }}$ val- 

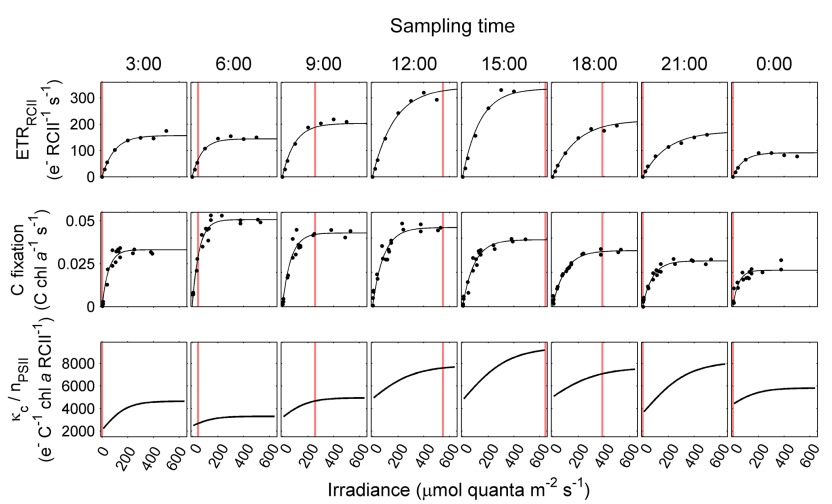

Figure 1. Diurnal variation in rates and light dependency of ETR $_{\mathrm{RCII}}$, carbon fixation, and the derived conversion factor $K_{\mathrm{c}} / n_{\mathrm{PSII}}$. P vs. E curves of $\mathrm{ETR}_{\mathrm{RCII}}\left(\mathrm{mol} \mathrm{e}^{-} \mathrm{molRCII}^{-1} \mathrm{~s}^{-1}\right)$ and carbon fixation ( $\mathrm{mol} \mathrm{C} \mathrm{mol} \mathrm{chl} a^{-1} \mathrm{~s}^{-1}$ ) were measured at $3 \mathrm{~h}$ intervals over a $24 \mathrm{~h}$ diurnal cycle. Data were fit to the exponential model of Webb et al. (1974). The conversion factor $K_{\mathrm{c}} / n_{\mathrm{PSII}}$ (mol $\mathrm{e}^{-} \mathrm{mol} \mathrm{C}^{-1} \mathrm{~mol} \mathrm{chl} a \mathrm{~mol} \mathrm{RCII}^{-1}$ ) and its light dependency were derived as the quotient of corresponding values of ETR $\mathrm{RCII}_{\mathrm{I}}$ and carbon fixation. The vertical line on plots corresponds to in situ PAR values at $5 \mathrm{~m}$ depth during sampling for each time point.

ues (> $\left.9000 \mathrm{~mol} \mathrm{e}^{-} \mathrm{mol} \mathrm{C}^{-1} \mathrm{~mol} \mathrm{chl} a \mathrm{~mol} \mathrm{RCII}{ }^{-1}\right)$ observed (Fig. 1).

From the $\mathrm{P}$ vs. $\mathrm{E}$ curves shown in Fig. 1 we derived the photosynthetic parameters $P_{\max }$ and $\alpha$ for both ETR $\mathrm{RCII}$ and carbon fixation (Fig. 2c-f). Over the diurnal cycle, the $P_{\max }-\mathrm{ETR}_{\mathrm{RCII}}$ changed by a factor of 3.2 and closely followed the incident irradiance (Fig. 2c), with peak values observed around solar noon. In contrast, $P_{\max }-\mathrm{C}$ was highest in the early morning and then steadily declined over the course of the day, changing by a factor of 2.5 over the diurnal cycle (Fig. 2e). The conversion factor $K_{\mathrm{c}} / n_{\mathrm{PSII}}$, derived for light-saturated photosynthesis $\left(P_{\max }-\mathrm{ETR}_{\mathrm{RCII}} / P_{\max }-\mathrm{C}\right)$, exhibited high values and a pronounced diurnal cycle, varying by a factor of 2.9 (Fig. $2 \mathrm{~g}$ ). Minimum values of $K_{\mathrm{c}} / n_{\text {PSII }}$ were observed early in the morning, while maximum values were observed during the afternoon.

The light use efficiency per incident quanta under subsaturating light conditions, $\alpha$, showed similar patterns to $P_{\max }$ for both ETR $_{\text {RCII }}$ and carbon fixation (Fig. 2). Values for $\alpha-$ ETR $_{\mathrm{RCII}}$ peaked during the late morning and then declined during the afternoon and into the evening (Fig. 2d). In contrast, $\alpha-\mathrm{C}$ was highest before sunrise and steadily decreased throughout the day (Fig. 2f). Over the course of the diurnal cycle, $\alpha-$ ETR $_{\mathrm{RCII}}$ changed by a factor of 1.9 while $\alpha-\mathrm{C}$ changed by a factor of 3.1. As with $P_{\max }$, the conversion factor $K_{\mathrm{c}} / n_{\text {PSII }}$ derived for $\alpha$ varied strongly (2.4-fold) over the diurnal cycle and showed maximum values during the afternoon, in conjunction with the highest incident PAR levels (Fig. 2h). At all TP, the conversion factor $K_{\mathrm{c}} / n_{\text {PSII }}$ was higher during light-saturated photosynthesis $\left(P_{\max }\right)$ than un-
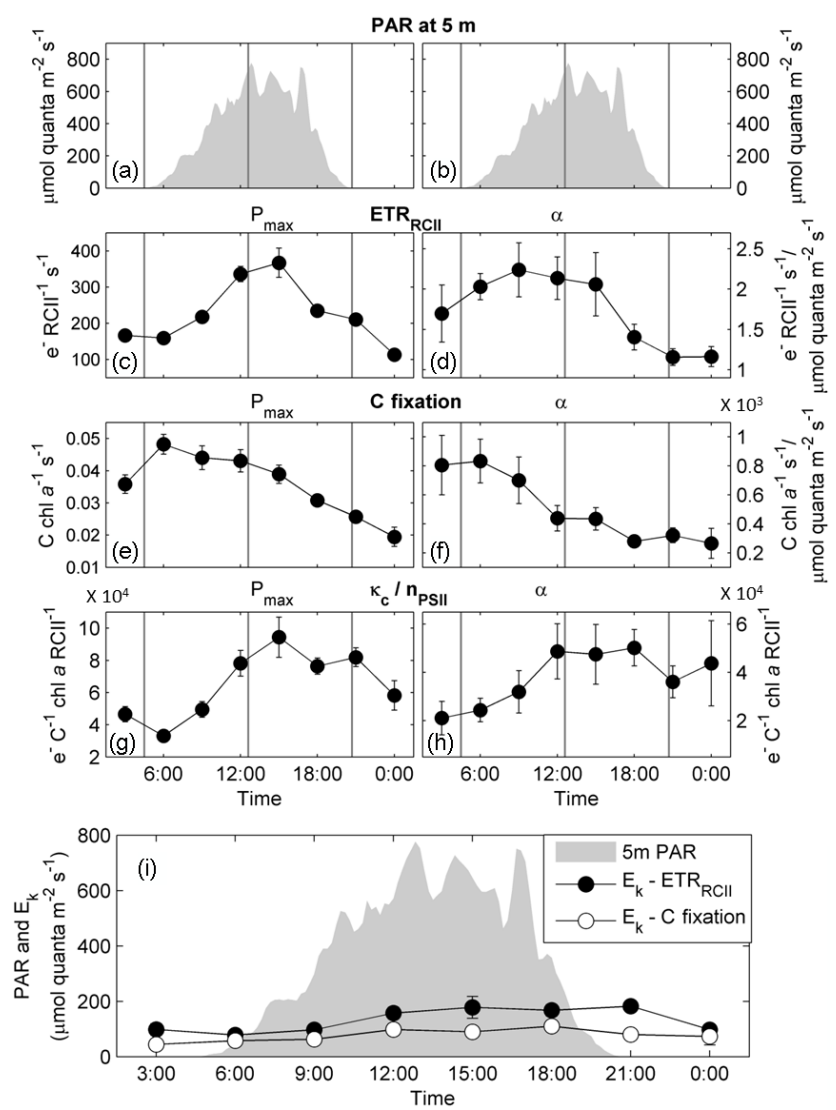

Figure 2. Diurnal changes in capacities and efficiencies of ETR $\mathrm{RCII}_{\mathrm{R}}$ and carbon fixation and the derived conversion factor $K_{\mathrm{c}} / n_{\mathrm{PSII}}$. The conversion factor $K_{\mathrm{c}} / n_{\mathrm{PSII}}$ at light saturation (g) is derived from the values in (c) and (e). Similarly, the conversion factor $K_{\mathrm{c}} / n_{\mathrm{PSII}}$ under light limiting conditions (h) is derived from values in (d) and (f). The error in (b), (c), (e), and (f) is the $95 \%$ confidence interval of the parameter derived from the fit to data shown in Fig. 1, and the error in (d) and (g) is the propagated error for (b) and (c) and (e) and (f), respectively. PAR at $5 \mathrm{~m}$ depth is shown in (a) and (b). The vertical gray lines in panels (a-h) mark sunrise, solar noon, and sunset. Panel (i) shows the light saturation parameter $E_{\mathrm{k}}$ for $\mathrm{ETR}_{\mathrm{RCII}}$ and carbon fixation in relation to in situ light availability.

der conditions of light limitation $(\alpha)$ (Fig. $2 \mathrm{~g}$ and h; note different scale of $y$ axis).

The light saturation point $E_{\mathrm{k}}$ was higher for $\mathrm{ETR}_{\mathrm{RCII}}$ than for carbon fixation at all TPs (Fig. 3), implying that carbon fixation rates saturated at lower light intensity than ETR $_{\text {RCII }}$. For both carbon fixation and ETR RCII $_{2} P_{\max }$ and $\alpha$ changed roughly in parallel (Fig. 2c-f). Consequently, diurnal changes in $E_{\mathrm{k}}$, derived as $P_{\max } / \alpha$, were relatively small (Fig. 2i). Furthermore, the relatively low values of $E_{\mathrm{k}}(\sim$ $100-150 \mu$ mol quantam $^{-2} \mathrm{~s}^{-1}$ ) indicate that both ETR $_{R C I I}$ and carbon fixation were saturated at in situ irradiance levels for most of the day (Fig. 2i).

Using the $\mathrm{P}$ vs. E curves measured for both $\mathrm{ETR}_{\mathrm{RCII}}$ and carbon fixation (Fig. 1), we derived rates correspond- 


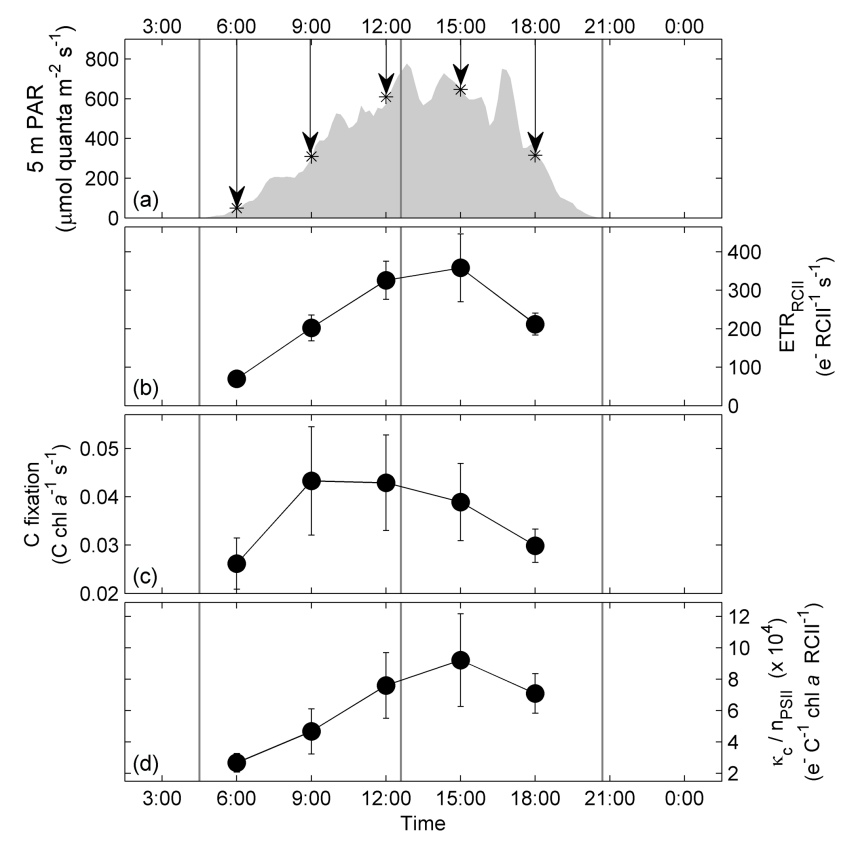

Figure 3. Diurnal changes in $E_{T} R_{R C I I}$, carbon fixation, and $K_{\mathrm{c}} / n_{\text {PSII }}$ derived for in situ light intensities at $5 \mathrm{~m}$ depth. Diurnal changes in irradiance at $5 \mathrm{~m}$ depth (a), with arrows indicating the PAR value used to derive rates in (b) and (c). Realized rates of $\operatorname{ETR}_{\mathrm{RCII}}(\mathbf{b})$ and carbon fixation (c) at each time point were derived from the P vs. E relationship established in Fig. 1. The error in (b) and (c) is the propagated $95 \%$ confidence interval of the parameter $\mathrm{P}$ vs. E fit parameters, and the error in (d) is the propagated error from (b)/(c). The vertical gray lines in all plots mark sunrise, solar noon, and sunset.

ing to the in $5 \mathrm{~m}$ irradiance levels at each TP (Fig. $3 \mathrm{~b}$ and c). Over the diurnal cycle, these derived in situ rates of ETR $_{\text {RCII }}$ changed by a factor of 5.1 (Fig. 3b), closely following changes in ambient irradiance levels (Fig. 3a), with peak values around noon. By comparison, carbon fixation derived for in situ light levels at $5 \mathrm{~m}$ depth changed by a factor of 1.7 over the period of our sampling (Fig. 3c). The maximum rate of realized carbon fixation at $5 \mathrm{~m}$ depth $\left(0.0433 \pm 0.0112 \mathrm{~mol} \mathrm{C} \mathrm{mol} \mathrm{chl} a^{-1} \mathrm{~s}^{-1}\right)$ was reached in the morning, well before the daily irradiance maximum (Fig. 3a and c). The derived in situ conversion factor $K_{\mathrm{c}} / n_{\text {PSII }}$ varied by a factor of 3.4. Lowest derived values of in situ $K_{\mathrm{c}} / n_{\text {PSII }}$ were observed early in the morning, after which values increased until reaching a maximum in the afternoon (Fig. 3d).

\subsection{Relative changes in $1 / n_{\text {PSII }}$}

Relative values of $1 / n_{\text {PSII }}$, shown in Fig. $4 a$, were highest in the early morning and then declined by $37 \%$ through the afternoon, with lowest values observed at midnight (Fig. 4a). The magnitude of diurnal change in $1 / n_{\text {PSII }}$ was significantly less than the diurnal changes observed in $K_{\mathrm{c}} / n_{\text {PSII }}$, which were 2.5-fold at in situ irradiances (Fig. 4b), 1.9-fold at light

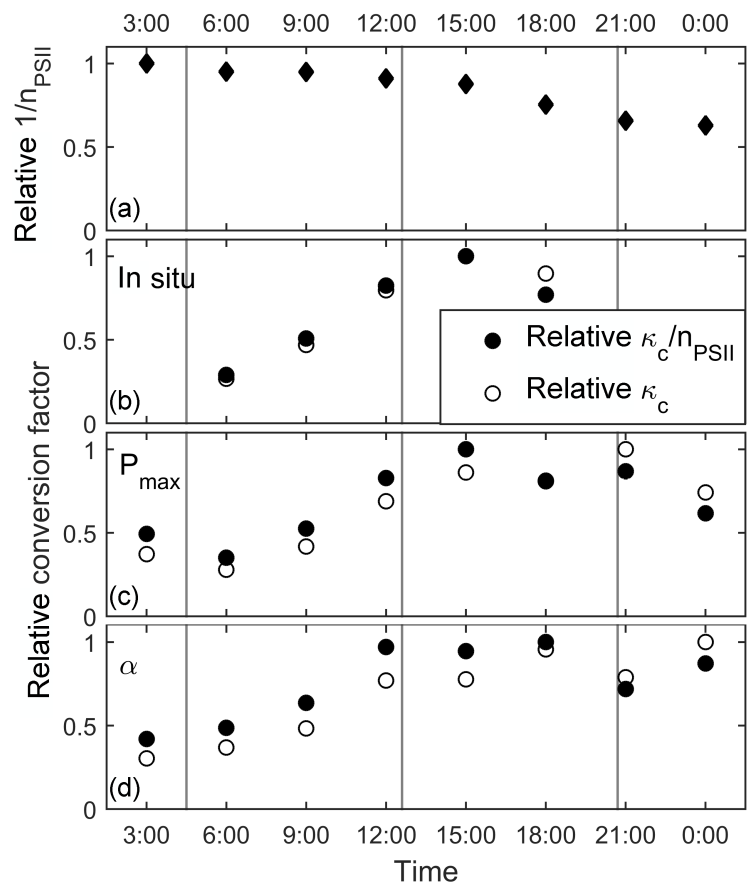

Figure 4. Relative changes in the components of the conversion factor $K_{\mathrm{c}} / n_{\text {PSII }}$ over the diurnal cycle. Panel (a) shows diurnal changes in $1 / n_{\mathrm{PSII}}$ ( $\mathrm{mol} \mathrm{chl} a \mathrm{~mol} \mathrm{RCII}^{-1}$ ), estimated as $\left(F_{\mathrm{O}} / \sigma_{\mathrm{PSII}}\right) /[\mathrm{chl} a]$. These relative values of $1 / n_{\mathrm{PSII}}$ were then used to derive relative values of $K_{\mathrm{c}}\left(\mathrm{mole}^{-} \mathrm{mol} \mathrm{C}^{-1}\right)$ from values of $K_{\mathrm{c}} / n_{\mathrm{PSII}}$. This was done for the conversion factor derived for in situ irradiances at $5 \mathrm{~m}$ depth (b), the conversion factor derived for light-saturated rates (c), and the conversion factor for light-limited rates (d). All values are scaled to 1 for clarity.

saturation $\left(P_{\max } ;\right.$ Fig. $\left.4 \mathrm{c}\right)$, and 1.4-fold at light limitation $(\alpha$, Fig. 4 d). We examined $K_{\mathrm{c}}$-specific variability by normalizing $K_{\mathrm{c}} / n_{\text {PSII }}$ estimates to the relative changes in $1 / n_{\text {PSII }}$. As shown in Fig. 4, the relative changes in $K_{\mathrm{c}}$ showed a diel pattern very similar to that observed for $K_{\mathrm{c}} / n_{\mathrm{PSII}}$ at in situ irradiances (Fig. 4b), at light saturation $\left(P_{\max }\right.$, Fig. $\left.4 \mathrm{c}\right)$, and under light limitation ( $\alpha$, Fig. $4 \mathrm{~d})$. This indicates that the observed diurnal variability in $K_{\mathrm{c}} / n_{\text {PSII }}$ was largely attributable to changes in $K_{\mathrm{c}}$.

\subsection{Photo-regulatory changes}

In addition to the apparent diurnal changes in carbon fixation and ETR $_{R C I I}$, we observed strong diurnal oscillations in a number of photophysiological parameters, as well as changes in pigment composition of the phytoplankton assemblage. While higher-resolution pigment data would have been desirable, the changes in pigment ratios shown in Fig. 5 indicate that the phytoplankton assemblage sampled from $5 \mathrm{~m}$ depth experienced supersaturating light conditions for a substantial part of the day.

The ratio of PPCs to total pigment (TPig), changed by a factor of 1.4 over the diurnal cycle, with lowest values ob- 


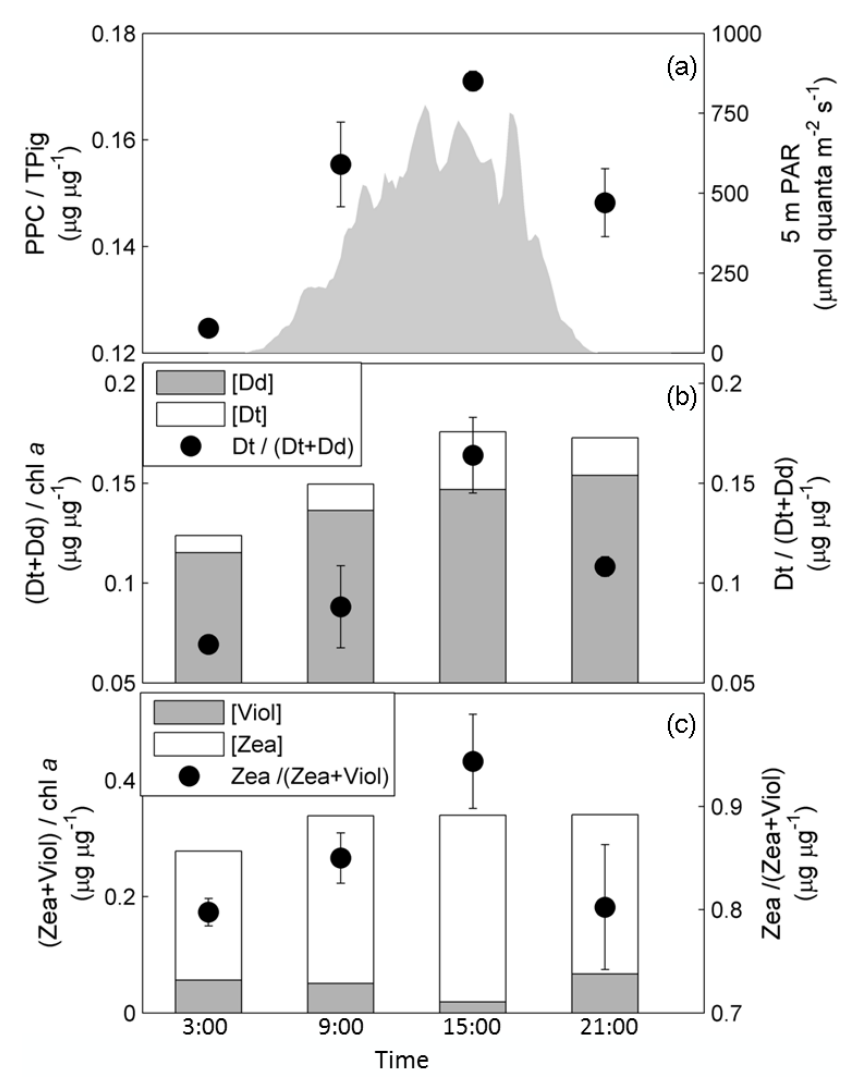

Figure 5. Diurnal changes in pigment ratios. Panel (a) shows changes in the abundance of all photoprotective pigment (PPC), relative to the total pigment present (TPig) at each time point. See Table 2 for a definition of pigment groups used to derive these ratios. Panel (b) shows relative changes in the abundance of the chromophyte xanthophyll-cycling pigments Dd and Dt, normalized to $[$ chl $a$ ]. Changes in the de-epoxidation state ration (DES ratio $=\mathrm{Dt} /(\mathrm{Dt}+\mathrm{Dd}))$, also shown in $(\mathbf{b})$, indicate the extent of active photoprotective energy dissipation through xanthophyll cycling in the pigment antenna. Similarly, panel (c) shows xanthophyll cycling pigments Viol and Zea, specific to prasinophytes and chlorophytes. Error bars are the range of values from two replicate samples taken at each time point.

served at the pre-dawn TP (03:00) and highest in the afternoon (15:00) (Fig. 5a). Similarly, the proportion of xanthophyll cycling (XC) pigments to total chl $a$ increased from pre-dawn (03:00) to midafternoon (15:00). This increase was observed in XC pigments specific to chromophytes ( $42 \%$ increase in $(\mathrm{Dd}+\mathrm{Dt}) / \mathrm{chl} a$; Fig. $5 \mathrm{~b})$ as well as chlorophyte and prasinophyte-specific XC pigments $(17 \%$ increase in (Zea + Viol) / chl $a$; Fig. 5 c). Changes in relative abundance of XC pigments indicate that a higher proportion of the pigment pool is dedicated to photoprotection.

In addition to changes in $\mathrm{XC}$ pigments, we also observed a 2.4-fold increase in the DES ratio (Dt / $(\mathrm{Dd}+\mathrm{Dt})$ ) of chromophyte algae between 03:00 and 15:00 (Fig. 5b) and a 1.8fold increase in the DES ratio of chlorophytes and prasino- phytes (Zea / (Zea + Viol), Fig. 5c). The changes in the DES ratio are an indicator of the activation of the photoprotective XC process (Brunet et al., 2011). Our results should be considered as conservative estimates of the DES ratios, given the potential for reversal of the high light-induced de-epoxidation during sample processing (samples were exposed to low light for approximately 30-60 min during sample collection and filtration). Notwithstanding the relatively low temporal resolution of our pigment samples, the observed changes in pigment ratios indicate that the phytoplankton assemblage sampled from $5 \mathrm{~m}$ depth experienced supersaturating light conditions for a substantial part of the day.

Further evidence for supersaturating light conditions in the mixed layer comes from observations of diurnal changes in PSII-specific photophysiological parameters derived from FRRF measurements (Fig. 6). Values of $F_{\mathrm{v}} / F_{\mathrm{m}}$, measured in the dark-regulated state, varied from 0.12 to 0.32 and showed an inverse relationship to irradiance (Fig. 6a), likely indicating downregulation or damage of PSII during high-irradiance conditions. The parameter $1 / \tau\left(\mathrm{m} \mathrm{s}^{-1}\right)$ is an estimate of the rate of electron transfer from the first stable electron acceptor $Q_{\mathrm{A}}$ to the second stable electron acceptor $Q_{\mathrm{B}}$. Values of $1 / \tau$ varied in parallel with available irradiance over the diurnal cycle, changing approximately 3 -fold, and indicating faster electron transport downstream of charge separation in RCII during daylight hours (Fig. 6b). Estimates of the expression of non-photochemical quenching, $\mathrm{NPQ}_{\mathrm{NSV}}$, at in situ (5 m depth) irradiance levels changed 7.6-fold over the diurnal cycle, with maximum values near the peak of solar irradiance (Fig. 6c). Spectrally corrected values of the functional absorption cross section of PSII, $\sigma_{\mathrm{PSII}}^{\prime}$, also derived for in situ irradiance levels, correlated inversely with irradiance (Fig. 6d). This decrease further confirms the induction of photoprotective mechanisms within the pigment antenna, preventing excess energy from reaching RCII. Photochemical quenching, estimated as $F^{\prime}{ }_{\mathrm{q}} / F^{\prime}{ }_{\mathrm{v}}$, indicates the fraction of RCII in the "open state", with the primary stable electron acceptor $Q_{\mathrm{A}}$ in the oxidized state (Roháček, 2002). Values of $F^{\prime}{ }_{\mathrm{q}} / F^{\prime}{ }_{\mathrm{v}}$, derived for a reference irradiance value of $500 \mu \mathrm{mol}$ quanta $\mathrm{m}^{-2} \mathrm{~s}^{-1}$ at all TP $\left(F_{\mathrm{q}}^{\prime}{ }_{\mathrm{q}} / F^{\prime}{ }_{\mathrm{v}}(500)\right)$, show significant change over the diurnal cycle, with midday values twice as high as those observed during the night (Fig. 6e).

\section{Discussion}

The experimental approach and results presented in this study confirm the hypothesized diurnal variation in the coupling of ETR $_{\mathrm{RCII}}$ and carbon fixation under iron-limited conditions.

Building on the work of others (Behrenfeld et al., 2004, 2008; Halsey and Jones, 2015), we interpret our results in the context of environmentally driven shifts in cellular energy allocation, which decouple photosynthesis from net growth 
on diurnal timescales. We speculate that the observed patterns are caused by photophysiological plasticity on a molecular level, which enables phytoplankton to maximize growth while minimizing photodamage under iron-limited conditions.

In the following, we first discuss diurnal variation at the level of carbon fixation and put our observations in context with the rich information available from the literature. We then consider the diurnal changes in ETR $\mathrm{RCII}_{\text {and the de- }}$ rived conversion factor $K_{\mathrm{c}} / n_{\text {PSII }}$ and discuss the relevance of our results to the development of FRRF-based phytoplankton primary productivity measurements.

\subsection{Diurnal changes in carbon fixation}

Diurnal variations in the capacity $\left(P_{\max }-\mathrm{C}\right)$, efficiency $(\alpha-\mathrm{C})$, and realized rates of carbon fixation are characteristic of phytoplankton assemblages in the natural environment and in laboratory cultures (Bruyant et al., 2005; Doblin et al., 2011; Doty and Oguri, 1957; Erga and Skjoldal, 1990; Harding et al., 1981, 1982, 1987; John et al., 2012; MacCaull and Platt, 1977; Prézelin, 1992; Stross et al., 1973; Zhao and Quigg, 2015). The general consensus is that carbon fixation is not passively regulated by the availability of light but by complex metabolic feedbacks and endogenous circadian rhythms.

For example, it has been shown that the expression of genes involved in carbon fixation peaks before dawn (Ashworth et al., 2013; Granum et al., 2009), "priming" cells to achieve maximum rates early in the day. High carbon fixation capacities $\left(P_{\max }-\mathrm{C}\right)$ before sunrise, as observed in our data (Fig. 2e), further confirm endogenous circadian control of this pathway.

In our data, $P_{\max }-\mathrm{C}$ and $\alpha-\mathrm{C}$ peaked early in the morning and covaried over the diurnal cycle (Fig. 2e and f). As a result, $E_{\mathrm{k}}$ (which is derived from the ratio of these parameters) remained relatively constant (Fig. $2 \mathrm{i}$ ). This " $E_{\mathrm{k}}$ independent" variability in the photosynthetic parameters $P_{\max }-\mathrm{C}$ and $\alpha-\mathrm{C}$ has long been considered somewhat enigmatic but is now accepted to be driven by shifts in cellular energy allocation (Behrenfeld et al., 2004, 2008; Bruyant et al., 2005; Halsey and Jones, 2015). In phytoplankton, the fraction of photosynthetically derived reductant (NADPH) and energy equivalent (ATP) allocated to carbon fixation and net growth as well as the ratio of NADPH : ATP produced are finely tuned to match metabolic demand. Metabolic demand, in turn, is a function of evolved endogenous rhythms and external environmental forcing. As discussed below, the decline in $P_{\max }-\mathrm{C}$ (Fig. 2e), $\alpha-\mathrm{C}$ (Fig. 2f), and realized rates of carbon fixation (Fig. 3c) after a peak in the early morning, is likely due to such shifts in energy allocation and to the damaging effects of excess light, which accumulate throughout the light period.

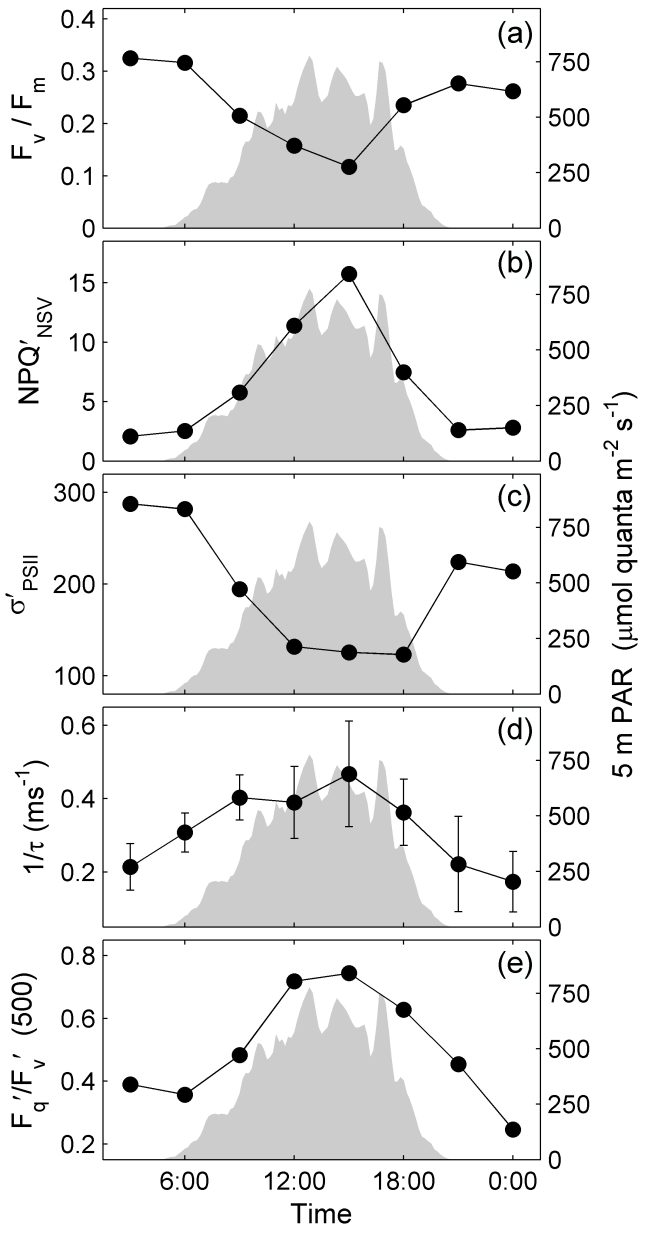

Figure 6. Diurnal changes in PSII photophysiological parameters derived from FRRF measurements. Panel (a) $F_{\mathrm{V}} / F_{\mathrm{m}}$ in the darkregulated state at each TP. Panels (b) and (c) show the normalized Stern-Volmer quenching, $\mathrm{NPQ}_{\mathrm{NSV}}$, derived as $F^{\prime}{ }_{\mathrm{o}} / F^{\prime}{ }_{\mathrm{V}}$ (McKew et al., 2013), and the functional absorption cross section, $\sigma_{\mathrm{PSII}}^{\prime}$, both estimated for in situ light availability at each TP. Values in (b) and (c) were calculated by extrapolating between values derived for each light step of the FRRF steady-state light curves. Panel (d) shows estimates of the rate of reoxidation of $Q_{\mathrm{A}}$. Panel (e) shows estimates of photochemical quenching $\left(F^{\prime}{ }_{\mathrm{q}} / F^{\prime}{ }_{\mathrm{v}}\right)$, indicating the fraction of open RCII (primary stable electron acceptor $Q_{\mathrm{A}}$ oxidized) at a reference irradiance level of $500 \mu \mathrm{mol}$ quanta $\mathrm{m}^{-2} \mathrm{~s}^{-1}$.

\subsection{Diurnal changes in ETR $_{\mathrm{RCII}}$ and the conversion factor $K_{\mathrm{c}} / \boldsymbol{n}_{\mathrm{PSII}}$}

In contrast to the diurnal cycles of carbon fixation, changes in $P_{\mathrm{max}}-\mathrm{ETR}_{\mathrm{RCII}}$ and $\alpha-\mathrm{ETR}_{\mathrm{RCII}}$ followed the availability of light more closely, peaking around noon (Fig. 2c, d). Simi-

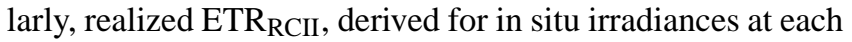
TP, correlated more closely to light availability than realized rates of carbon fixation (Fig. 3b). While it has been demonstrated that virtually all stages of photosynthesis exhibit circadian control (Suzuki and Johnson, 2001), our results sug- 
gests that $\mathrm{ETR}_{\mathrm{RCII}}$ responds more directly to changes in light availability than the subsequent conversion of light energy into cellular organic carbon. It is important to note that the accumulation of photodamage and inhibition over the course of the light period is likely to impart some level of hystere-

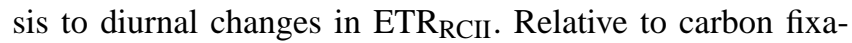
tion, however, our results show that $\mathrm{ETR}_{\mathrm{RCII}}$ is much more closely tied to instantaneous changes in light availability. The resulting decoupling of carbon fixation and photosynthetic electron transport is reflected in the diurnal variability in $K_{\mathrm{c}} / n_{\text {PSII }}$ (Figs. $2 \mathrm{~g}, \mathrm{~h}, 3 \mathrm{~d}$ ). Based on our estimates of relative changes in $1 / n_{\text {PSII }}$ over the diel cycle (Fig. 4 ), we conclude that the majority of diurnal variability in $K_{\mathrm{c}} / n_{\mathrm{PSII}}$ results from changes in $K_{\mathrm{c}}$.

In our data set, in situ values for $K_{\mathrm{c}} / n_{\text {PSII }}$ ranged from 2700 to $9200 \mathrm{~mol} \mathrm{e}^{-} \mathrm{mol} \mathrm{C}^{-1} \mathrm{~mol} \mathrm{chl} a \mathrm{~mol} \mathrm{RCII}^{-1}$. For a constant $1 / n_{\text {PSII }}$ of $500 \mathrm{~mol} \mathrm{chl} a \mathrm{~mol} \mathrm{RCII}^{-1}$ (Kolber and Falkowski, 1993), the derived $K_{\mathrm{c}}$ ranges from 5 to $18 \mathrm{~mol} \mathrm{e}^{-}$mol C, which is within the range of previously reported values (Lawrenz et al., 2013) and above the theoretical minimum of $4 \mathrm{~mol} \mathrm{e}^{-} \mathrm{molC}$. If we take into account the estimated relative changes in $1 / n_{\text {PSII }}$ (Sect. 3.4, Fig. 4), we can assume $1 / n_{\text {PSII }}$ to decrease from $700 \mathrm{~mol} \mathrm{chl} a \mathrm{~mol} \mathrm{RCII}^{-1}$ at TP 1 (03:00) to 440 at TP 8 (00:00). This, in turn, can be used to estimate values of $K_{\mathrm{c}}$ to range from $4 \mathrm{~mol} \mathrm{e}^{-} \mathrm{molC}$ in the morning (TP 2, 06:00) to $13 \mathrm{~mol} \mathrm{e}^{-} \mathrm{mol} \mathrm{C}^{-1}$ in the afternoon (TP 5, 15:00).

The large diurnal variability in $\mathrm{ETR}_{\mathrm{RCII}}$ and carbon fixation and the highly variable $K_{\mathrm{c}} / n_{\text {PSII }}$, reflect the integrated growth environment experienced by the sampled phytoplankton assemblage. The lowest values of $K_{\mathrm{c}} / n_{\text {PSII }}$ were observed early in the morning (Fig. 3d), indicating that much of the energy harvested from sunlight and converted into chemical energy was used directly for carbon fixation. Thereafter, the conversion factor $K_{\mathrm{c}} / n_{\mathrm{PSII}}$ increased rapidly, reaching a maximum in the afternoon (Fig. 3d).

Diurnal variation in $K_{\mathrm{c}} / n_{\text {PSII }}$ can result from a number of interconnected cell physiological mechanisms aimed at the rebalancing of energy and/or reductant. Firstly, it is possible that diurnal oscillations in cell metabolism result in changes inorganic carbon respiration and/or excretion. In our $3.5 \mathrm{~h}{ }^{14} \mathrm{C}$-uptake experiments, transient organic carbon pools destined for respiration or excretion could have been captured to different extents, affecting the derived conversion factor $K_{\mathrm{c}} / n_{\text {PSII }}$. Changes in cellular energy allocation, controlled in part by endogenous circadian rhythms, could also have affected the conversion factor $K_{\mathrm{c}} / n_{\mathrm{PSII}}$, by rerouting NADPH and ATP generated by the photosynthetic light reaction to processes other than carbon fixation, thus increasing $K_{\mathrm{c}} / n_{\text {PSII }}$. Processes decoupling ETR $\mathrm{RCII}_{\text {from carbon fixa- }}$ tion include nutrient assimilation (Laws, 1991), carbon concentrating mechanisms (Giordano et al., 2005), photorespiration (Foyer et al., 2009), and malate formation (Halsey and Jones, 2015). Pseudo-cyclic electron transport through the Mehler-ascorbate peroxidase pathway also has the ability to increase the conversion factor $K_{\mathrm{c}} / n_{\mathrm{PSII}}$ by allowing $\mathrm{ETR}_{\mathrm{RCII}}$ to increase without affecting carbon fixation (Miyake and Asada, 2003; Niyogi, 2000). Moreover, processes acting before photosystem I (PSI) can decouple $\mathrm{ETR}_{\mathrm{RCII}}$ and carbon fixation by "syphoning" electrons out of the ETC to alleviate over-reduction under supersaturating light condition. Pseudo-cyclic electron transport though midstream terminal oxidases (Bailey et al., 2008; Mackey et al., 2008), cyclic electron transport around PSII (Feikema et al., 2006; Prasil et al., 1996), and charge recombination in RCII (Vass, 2011) could all be important under high midday irradiances. These processes would all act to increase $E_{T R} R_{R C I I}$ without affecting $\mathrm{CO}_{2}$ assimilation, thus leading to a higher conversion factor $K_{\mathrm{c}} / n_{\text {PSII }}$.

Iron limitation, as experienced by the phytoplankton assemblage we sampled, directly affects the functioning of the ETC, which is rich in iron-containing redox-chain components (Raven et al., 1999; Yruela, 2013). It is thus likely that the need for safe dissipation of excess excitation pressure after charge separation in RCII is enhanced under iron limitation (Behrenfeld and Milligan, 2013; Schuback et al., 2015), leading to a greater decoupling of $\mathrm{ETR}_{\mathrm{RCII}}$ and carbon fixation (Schuback et al., 2015). Pseudo-cyclic electron flow could alleviate over-reduction of the ETC under ironlimiting conditions, while also contributing to ATP production (Behrenfeld and Milligan, 2013). The resulting increase in the cellular ATP: NADPH ratio would match the shift in energy demand from growth (higher NADPH requirement) to maintenance (higher ATP requirement), which takes place under nutrient-limited growth conditions.

While the exact nature and extent of operation of these various pathways and their actual influence on the coupling of ETR $\mathrm{RCII}_{\text {and }}$ carbon fixation remains to be verified, we suggest that the observed changes in the conversion factor $K_{\mathrm{c}} / n_{\text {PSII }}$ over the diurnal cycle reflect the interactions of external phasing of photosynthetic metabolism by the availability of light and internal metabolic rhythms in cell metabolism, which optimize energy allocation and growth under iron-limited conditions.

\subsection{Diurnal changes in photophysiology at the level of PSII}

In our data, several lines of evidence demonstrate that the phytoplankton assemblage we sampled from $5 \mathrm{~m}$ depth experienced supersaturating irradiance during part of the day. A suite of mechanisms was activated to dissipate the excess excitation energy in the pigment antenna before it could reach RCII. This was indicated by changes in pigment ratios (Fig. 5) and FRRF-derived photophysiological parameters (Fig. 6). The light harvesting antennae of phytoplankton are comprised of both photosynthetic and photoprotective pigments, the relative abundance of which can change in response to irradiance. The ratio [PPC] / [TPig], provides information on the degree of high light acclima- 
tion of a mixed phytoplankton assemblage (Brunet et al., 2011). In our data, [PPC] / [TPig] increased during the day (Fig. 5a), indicating that the phytoplankton assemblage experienced and responded to supersaturating irradiance levels. Furthermore, significant changes in the DES ratio of chromophytes (Dt / (Dt + Dd), Fig. 5b), as well as chlorophytes and prasinophytes (Zea / (Zea + Viol), Fig. 5c) illustrate rapid activation of photoprotective energy dissipation in the pigment antenna in response to diurnal changes in irradiance (Brunet et al., 2011).

Figure 6 shows pronounced diurnal variability in a number of FRRF-derived parameters. Both $F_{\mathrm{v}} / F_{\mathrm{m}}$ (Fig. 6a) and $1 / \tau$ (Fig. 6d) were derived for the dark-regulated state at each TP. To reach this dark-regulated state, samples were kept under very low light for a minimum of 30 min prior to the measurement. In theory, such low-light incubation allows for oxidation of the ETC and relaxation of all NPQ processes, enabling the measurement of maximum ChlF yields. In practice, however, a fully dark-regulated state cannot be achieved in natural phytoplankton assemblages, where optimal dark-acclimation times can be on the order of hours (From et al., 2014) and would depend on recent light history and taxonomic composition. Consequently, the interpretation of ChlF yields and parameters in field phytoplankton assemblages should be treated with caution. Notwithstanding these caveats, the FRRF-derived ChlF yields and parameters shown in Fig. 6 show clearly that, at the level of PSII, the sampled phytoplankton assemblage experienced and reacted to excess irradiance.

While it is known that nutritional state and taxonomy both strongly influence values of $F_{\mathrm{v}} / F_{\mathrm{m}}$ (Suggett et al., 2009), it is very unlikely that changes in either are responsible for the pronounced diurnal cycle of $F_{\mathrm{v}} / F_{\mathrm{m}}$ observed in our data (Fig. 6a). We therefore attribute the midday decrease in $F_{\mathrm{v}} / F_{\mathrm{m}}$ to persistent photoprotective changes and photoinhibition in PSII (Öquist et al., 1992), which are likely enhanced under iron limitation (Suzuki, 2002).

Processes including the light-induced changes in pigment composition shown in Fig. 5, act to dissipate excess excitation pressure in the pigment antenna before reaching RCII. These processes also quench ChlF yields, as measured by FRRF. Consequently, so-called non-photochemical quenching (NPQ), as estimated from FRRF measurements, has been widely used as an estimate for photoprotective energy dissipation (Demmig-Adams et al., 2014; Derks et al., 2015). NPQ encompasses a wide variety of mechanisms, all acting to dissipate absorbed light energy as heat before it reaches RCII (e.g., Derks et al., 2015). Following the approach of McKew et al. (2013), we estimated NPQ from FRRF measurements as so-called normalized Stern-Volmer quenching (NPQNSV). The 7.6-fold change in $\mathrm{NPQ}_{\mathrm{NSV}}$, estimated for in situ light availability at $5 \mathrm{~m}$ depth (Fig. 6b), confirms that the phytoplankton assemblage sampled experienced, and rapidly reacted to, supersaturating light conditions. The inverse light dependence of the functional absorption cross sec- tion of PSII, $\sigma_{\mathrm{PSII}}^{\prime}$, derived for in situ irradiances at each TP (Fig. 6c), provides a further illustration of rapid changes taking place in the pigment antenna to prevent excess excitation energy from reaching RCII.

In addition to the protective mechanisms acting in the pigment antenna to prevent charge separation in RCII, photoprotective mechanisms also act after charge separation in RCII (Sect. 4.2). These mechanisms alleviate over-reduction by allowing rapid reoxidation of the primary stable electron acceptor $Q_{\mathrm{A}}$. Our data show evidence of the upregulation of such alternative electron sinks during midday. Figure $6 \mathrm{~d}$ shows a light-dependent increase in $1 / \tau$, which provides an estimate of the rate of reoxidation of the first stable electron acceptor $Q_{\mathrm{A}}$. Increased $1 / \tau$ thus suggests faster electron flow downstream from $Q_{\mathrm{A}}$, which is consistent with the upregulation of alternative electron sinks. Further support for this idea comes from diel changes in the estimated fraction of $Q_{\mathrm{A}}$ in the oxidized state $\left(F_{\mathrm{q}}^{\prime} / F^{\prime}{ }_{\mathrm{v}}\right)$, derived for a reference irradiance of $500 \mu \mathrm{mol}$ quanta $\mathrm{m}^{-2} \mathrm{~s}^{-1}$ (Fig. 6e). The midday increase in the oxidized fraction of $Q_{\mathrm{A}}$ at a constant saturating irradiance of $500 \mu \mathrm{mol}$ quanta $\mathrm{m}^{-2} \mathrm{~s}^{-1}$ strongly suggests the upregulation of alternative electron sinks, which most likely serve a photoprotective function (Mackey et al., 2008). Upregulation of these photoprotective mechanisms influences the coupling between electron transport and carbon fixation and thus directly affects the conversion factor $K_{\mathrm{c}} / n_{\text {PSII }}$ (see Sect. 4.2).

\subsection{Linking $K_{\mathrm{c}} / n_{\mathrm{PSII}}$ and NPQ $Q_{\mathrm{NSV}}$}

As discussed above, excess excitation energy leads to the induction of processes preventing energy transfer to RCII, and to processes acting to prevent over-reduction of the ETC after charge separation. NPQNSV provides an estimate of thermal energy dissipation upstream of RCII, which acts to prevent excess electron transport and over-reduction of the ETC. Downstream changes in electron flow after charge separation at RCII are reflected in changes in $K_{\mathrm{c}} / n_{\text {PSII }}$, through the induction of various mechanisms, as discussed in the previous section. Following the approach of Schuback et al. (2015), we examined the correlation between the derived conversion

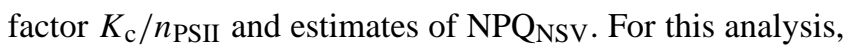
we used estimates of NPQ $\mathrm{NSV}_{\mathrm{N}}$ for each light level and TP of the FRRF light curves and derived values of $K_{\mathrm{c}} / n_{\text {PSII }}$ by extrapolation along the carbon fixation and ETR $\mathrm{RCII}_{\mathrm{I}}$ based $\mathrm{P}$ vs. E curves. As shown in Fig. 7, we found a strong correlation between these two variables $\left(R^{2}=0.81, p\right.$ value $<0.0001$, $n=64)$.

As described in detail in Schuback et al. (2015), the observed empirical correlation between $K_{\mathrm{c}} / n_{\mathrm{PSII}}$ and NPQNSV can be rationalized in terms of photophysiological mechanisms, acting to dissipate excess excitation energy both upstream and downstream of charge separation in RCII. The dissipation of excess excitation energy as thermal energy before reaching RCII, estimated as $\mathrm{NPQ}_{\mathrm{NSV}}$, prevents excess 
electron transport and over-reduction of the ETC. After the initial charge separation in RCII, excess electron transport and over-reduction of the ETC can be alleviated by a number of alternative electron pathways; the upregulation of which will increase $K_{\mathrm{c}} / n_{\text {PSII }}$ (e.g., Bailey et al., 2008; Cardol et al., 2011; Laureau et al., 2013; Mackey et al., 2008; McDonald et al., 2011; Niyogi, 2000; Streb et al., 2005; Vass, 2011; Zehr and Kudela, 2009). Thus, both NPQNSV and $K_{\mathrm{c}} / n_{\mathrm{PSII}}$ respond strongly to excess excitation pressure, providing a possible mechanistic interpretation for their correlation. In fact, a positive feedback loop exists between energy dissipation in the antenna and photosynthetic control in the ETC because alternative electron pathways enhance the transmembrane $\Delta \mathrm{pH}$, which triggers several components of NPQ (Nawrocki et al., 2015). The correlation between NPQNSV and $K_{\mathrm{c}} / n_{\mathrm{PSII}}$ is likely to be especially strong under iron-limiting conditions, due to the enhancement of energy dissipation mechanisms when the functioning of the ETC is comprised by the availability of iron (Schuback et al., 2015).

While a correlation between $\mathrm{NPQ}_{\mathrm{NSV}}$ and $K_{\mathrm{c}} / n_{\mathrm{PSII}}$ has important implications for the derivation of carbon-based primary productivity rates from FRRF measurements, the correlation can be confounded by ambiguity and inherent biases in the derivation of all involved parameters. For example, while the correlations between NPQNSV and $K_{\mathrm{c}} / n_{\mathrm{PSII}}$ in the present, as well as in our previously published data set (Schuback et al., 2015), are strong, their regression slopes differ. The observed discrepancy could be explained in several ways. Firstly, data in our previous study were not corrected for spectral differences between the FRRF instrument, the ${ }^{14} \mathrm{C}$-uptake experiments and in situ light. As a consequence, absolute values of the derived conversion factor were likely overestimated. Furthermore, data presented in Schuback et al. (2015) included phytoplankton assemblages sampled over a range of iron-limited and iron-replete conditions. The resulting variability in phytoplankton growth rates influences the balance between net and gross carbon fixation captured in $3 \mathrm{~h}{ }^{14} \mathrm{C}$-uptake experiments (Halsey et al., 2011; Milligan et al., 2015; Pei and Laws, 2013) and affects the derived conversion factor $K_{\mathrm{c}} / n_{\mathrm{PSII}}$.

More generally, significant uncertainty remains in the es-

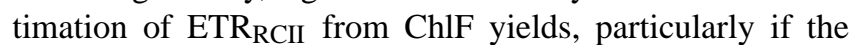
theoretical biophysical models are applied to mixed phytoplankton assemblages containing species with contrasting photosynthetic architectures and photophysiological characteristics. Inherent biases and potential systematic errors in

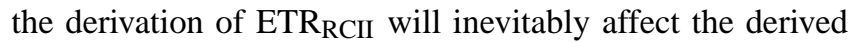
conversion factor $K_{\mathrm{c}} / n_{\text {PSII }}$. Similarly, it remains unclear if the quenching of ChlF yields, used to derive NPQ, correlate linearly with increases in thermal energy dissipation in the pigment antenna (Derks et al., 2015). Ultimately, larger data sets, spanning multiple oceanic regions and phytoplankton assemblages of contrasting taxonomic composition and physiological state are needed to further investigate the correlation between NPQNSV and $K_{\mathrm{c}} / n_{\mathrm{PSII}}$.

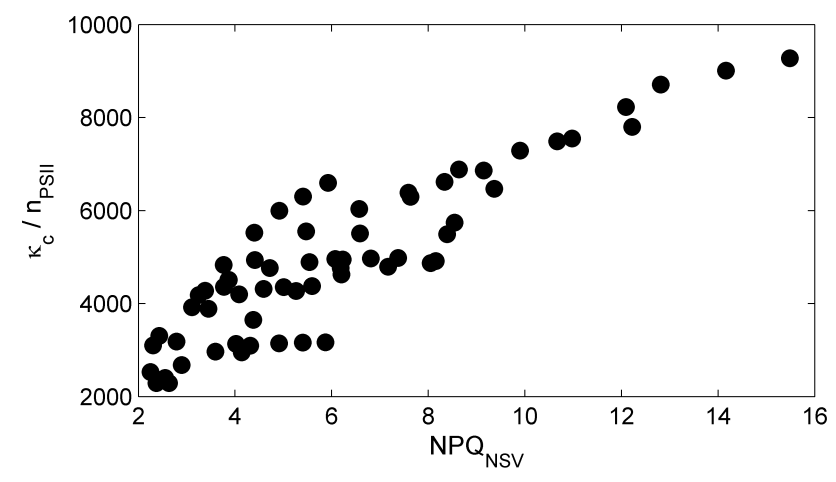

Figure 7. Correlation between the conversion factor $K_{\mathrm{c}} / n_{\mathrm{PSII}}$ and the expression of $\mathrm{NPQ}_{\mathrm{NSV}}$. NPQ $\mathrm{NSV}_{\mathrm{N}}$ was derived as $F^{\prime}{ }_{\mathrm{o}} / F^{\prime}{ }_{\mathrm{v}}$ (McKew et al., 2013), for each step of the FRRF light curve at each TP. Values of $K_{\mathrm{c}} / n_{\text {PSII }}$ corresponding to the same light intensities were derived by extrapolation along the carbon fixation and ETR $_{\text {RCII }}$-based P vs. E curves.

\section{Conclusions}

The lure of FRRF instruments lies in their potential for autonomous, instantaneous data acquisition at high temporal and spatial resolution. However, uncertainty in the conversion factor needed to convert rates of $\mathrm{ETR}_{\mathrm{RCII}}$ into ecologically relevant rates of carbon fixation remains a significant challenge. Through a suite of photophysiological data and ancillary measurements, our results provide some insight into the potential mechanistic causes leading to an uncoupling

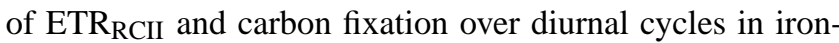
limited phytoplankton assemblages. Beyond providing improved methods to estimate phytoplankton carbon fixation rates, information on magnitude and variability of the conversion factor linking ETR $_{R C I I}$ and carbon fixation allows a better mechanistic understanding of how phytoplankton harvest and allocate light energy in response to environmental conditions. Our mechanistic understanding of these processes is crucial for the modeling and prediction of patterns in marine primary productivity in the face of climate-dependent changes in oceanic ecosystems.

More generally, it is important to consider that the dynamics of marine productivity over long timescales are ultimately controlled by interactions among biological and physical processes that have strong diurnal components. Several recent studies suggest a previously underappreciated importance of closely coupled diurnal oscillations as the underlying mechanisms of ecosystem stability in open ocean food webs (Ottesen et al., 2014; Ribalet et al., 2015). Our results show strong diurnal variability in photophysiology and cell metabolism of mixed phytoplankton assemblages. These physiological processes likely influence the phasing and periodicity of higher trophic-level processes and may ultimately contribute to conveying stability to the system. 
Acknowledgements. The authors thank Marie Robert and the scientific and coast guard crews on board CCGS John P. Tully during Line-P 2014-18. We would further like to thank Z. Kolber for assistance with the FRRF instrument and C. Hoppe and D. Semeniuk for their critical reading of earlier versions of the manuscript. We furthermore thank three anonymous reviewers for their insightful comments and suggestions.

Edited by: K. Suzuki

\section{References}

Arrigo, K. R., Mills, M. M., Kropuenske, L. R., Dijken, G. L. van, Alderkamp, A.-C., and Robinson, D. H.: Photophysiology in two major southern ocean phytoplankton taxa: photosynthesis and growth of Phaeocystis antarctica and Fragilariopsis cylindrus under different irradiance levels, Integr. Comp. Biol., 50, 950966, doi:10.1093/icb/icq021, 2010.

Ashworth, J., Coesel, S., Lee, A., Armbrust, E. V., Orellana, M. V., and Baliga, N. S.: Genome-wide diel growth state transitions in the diatom Thalassiosira pseudonana, P. Natl. Acad. Sci. USA, 110, 7518-7523, doi:10.1073/pnas.1300962110, 2013.

Bailey, S., Melis, A., Mackey, K. R. M., Cardol, P., Finazzi, G., van Dijken, G., Berg, G. M., Arrigo, K., Shrager, J., and Grossman, A.: Alternative photosynthetic electron flow to oxygen in marine Synechococcus, Biochim. Biophys. Acta, 1777, 269-276, doi:10.1016/j.bbabio.2008.01.002, 2008.

Barwell-Clarke, F. W.: Institute of Ocean Sci.s Nutrient Methods and Analysis, Can. Tech. Rep. Hydrogr. Ocean Sci., 182, 43 pp., 1996.

Behrenfeld, M. J. and Milligan, A. J.: Photophysiological expressions of iron stress in phytoplankton, Annu. Rev. Mar. Sci., 5, 217-246, doi:10.1146/annurev-marine-121211-172356, 2013.

Behrenfeld, M. J., Prasil, O., Babin, M., and Bruyant, F.: In search of a physiological basis for covariations in light-limited and light-saturated photosynthesis, J. Phycol., 40, 4-25, 2004.

Behrenfeld, M. J., Halsey, K. H., and Milligan, A. J.: Evolved physiological responses of phytoplankton to their integrated growth environment, Philos. Trans. R. Soc. B, 363, 2687-2703, 2008.

Bilger, W. and Björkman, O.: Role of the xanthophyll cycle in photoprotection elucidated by measurements of lightinduced absorbance changes, fluorescence and photosynthesis in leaves of Hedera canariensis, Photosynth. Res., 25, 173-185, doi:10.1007/BF00033159, 1990.

Brunet, C., Johnsen, G., Lavaud, J., and Roy, S.: Pigments and photoacclimation processes, Phytoplankton Pigments Charact. Chemotaxon, Appl. Oceanogr., available at: https:// hal.archives-ouvertes.fr/hal-01101814/ (last access: $29 \mathrm{Au}-$ gust 2015), 2011.

Bruyant, F., Babin, M., Genty, B., Prasil, O., Behrenfeld, M. J., Claustre, H., Bricaud, A., Garczarek, L., Holtzendorff, J., and Koblizek, M.: Diel variations in the photosynthetic parameters of Prochlorococcus strain PCC 9511: combined effects of light and cell cycle, Limnol. Oceanogr., 50, 850-863, 2005.

Cardol, P., Forti, G., and Finazzi, G.: Regulation of electron transport in microalgae, Biochim. Biophys. Acta, 1807, 912-918, 2011.
Cheah, W., McMinn, A., Griffiths, F. B., Westwood, K. J., Wright, S. W., Molina, E., Webb, J. P., and van den Enden, R.: Assessing Sub-Antarctic Zone primary productivity from fast repetition rate fluorometry, Deep-Sea Res. Pt. II, 58, 2179-2188, doi:10.1016/j.dsr2.2011.05.023, 2011.

Corno, G., Letelier, R. M., Abbott, M. R., and Karl, D. M.: Assesing primary production variability in the North Pacific Subtropical Gyre: a comparison of fast repetition rate fluorometry and ${ }^{14} \mathrm{C}$ measurements, J. Phycol., 42, 51-60, 2006.

Demmig-Adams, B., Garab, G., Adams III, W., and Govindjee (Eds.): Non-Photochemical Quenching and Energy Dissipation in Plants, Algae and Cyanobacteria, Springer Netherlands, Dordrecht, available at: http://link.springer.com/10.1007/ 978-94-017-9032-1 (last access: 9 June 2015), 2014.

Derks, A., Schaven, K., and Bruce, D.: Diverse mechanisms for photoprotection in photosynthesis. Dynamic regulation of photosystem II excitation in response to rapid environmental change, Biochim. Biophys. Acta, 1847, 468-485, doi:10.1016/j.bbabio.2015.02.008, 2015.

Doblin, M. A., Petrou, K. L., Shelly, K., Westwood, K., van den Enden, R., Wright, S., Griffiths, B., and Ralph, P. J.: Diel variation of chlorophyll $a$ fluorescence, phytoplankton pigments and productivity in the Sub-Antarctic and Polar Front Zones south of Tasmania, Australia, Deep-Sea Res. Pt. II, 58, 2189-2199, doi:10.1016/j.dsr2.2011.05.021, 2011.

Doty, M. S. and Oguri, M.: Evidence for a photo synthetic daily periodicity, Limnol. Oceanogr., 2, 37-40, doi:10.4319/lo.1957.2.1.0037, 1957.

Erga, S. R. and Skjoldal, H. R.: Diel variations in photosynthetic activity of summer phytoplankton in Linda aspollene, western Norway, available at: http://brage.bibsys.no/xmlui/handle/ 11250/108310 (last access: 8 September 2015), 1990.

Feikema, O. W., Marosvölgyi, M. A., Lavaud, J., and van Gorkom, H. J.: Cyclic electron transfer in photosystem II in the marine diatom Phaeodactylum tricornutum, Biochim. Biophys. Acta, 1757, 829-834, doi:10.1016/j.bbabio.2006.06.003, 2006.

Field, C. B., Behrenfeld, M. J., Randerson, J. T., and Falkowski, P.: Primary production of the biosphere: integrating terrestrial and oceanic components, Science, 281, 237-240, 1998.

Foyer, C. H., Bloom, A. J., Queval, G., and Noctor, G.: Photorespiratory metabolism: genes, mutants, energetics, and redox signaling, Annu. Rev. Plant Biol., 60, 455-484, doi:10.1146/annurev.arplant.043008.091948, 2009.

From, N., Richardson, K., Mousing, E. A., and Jensen, P. E.: Removing the light history signal from normalized variable fluorescence $\left(F_{\mathrm{V}} / F_{\mathrm{m}}\right)$ measurements on marine phytoplankton, Limnol. Oceanogr.-Meth., 12, 776-783, doi:10.4319/lom.2014.12.776, 2014.

Fujiki, T., Suzue, T., Kimoto, H., and Saino, T.: Photosynthetic electron transport in Dunaliella tertiolecta (Chlorophyceae) measured by fast repetition rate fluorometry: relation to carbon assimilation, J. Plankton Res., 29, 199-208, 2007.

Giordano, M., Beardall, J., and Raven, J. A.: $\mathrm{CO}_{2}$ concentatrating mechanisms in algae: mechanisms, environmental modulation, and evolution, Annu. Rev. Plant Biol., 56, 99-131, doi:10.1146/annurev.arplant.56.032604.144052, 2005.

Granum, E., Roberts, K., Raven, J. A., and Leegood, R. C.: Primary carbon and nitrogen metabolic gene expression in the diatom Thalassiosira Pseudonana (bacillariophyceae): diel period- 
icity and effects of inorganic carbon and nitrogen, J. Phycol., 45, 1083-1092, doi:10.1111/j.1529-8817.2009.00728.x, 2009.

Halsey, K. H. and Jones, B. M.: Phytoplankton strategies for photosynthetic energy allocation, Annu. Rev. Mar. Sci., 7, 265-297, doi:10.1146/annurev-marine-010814-015813, 2015.

Halsey, K. H., Milligan, A. J., and Behrenfeld, M. J.: Linking timedependent carbon-fixation efficiencies in Dunaliella Tertiolecta (chlorophyceae) to underlying metabolic pathways, J. Phycol., 47, 66-76, doi:10.1111/j.1529-8817.2010.00945.x, 2011.

Harding, L. W., Meeson, B. W., Prézelin, B. B., and Sweeney, B. M.: Diel periodicity of photosynthesis in marine phytoplankton, Mar. Biol., 61, 95-105, doi:10.1007/BF00386649, 1981.

Harding, L. W., Prezelin, B. B., Sweeney, B. M., and Cox, J. L.: Primary production as influenced by diel periodicity of phytoplankton photosynthesis, Mar. Biol., 67, 179-186, 1982.

Harding, L. W., Fisher, T. R., and Tyler, M. A.: Adaptive responses of photosynthesis in phytoplankton: specificity to time-scale of change in light, Biol. Oceanogr., 4, 403-437, doi:10.1080/01965581.1987.10749499, 1987.

John, D. E., López-Díaz, J. M., Cabrera, A., Santiago, N. A., Corredor, J. E., Bronk, D. A., and Paul, J. H.: A day in the life in the dynamic marine environment: how nutrients shape diel patterns of phytoplankton photosynthesis and carbon fixation gene expression in the Mississippi and Orinoco River plumes, Hydrobiologia, 679, 155-173, 2012.

Kaiblinger, C. and Dokulil, M. T.: Application of fast repetition rate fluorometry to phytoplankton photosynthetic parameters in freshwaters, Photosynth. Res., 88, 19-30, 2006.

Kirk, J. T. O.: Light and Photosynthesis in Aquatic Ecosystems, Cambridge University Press, Cambridge, 2011.

Kishino, M., Takahashi, M., Okami, N., and Ichimura, S.: Estimation of the spectral absorption coefficients of phytoplankton in the sea, Bull. Mar. Sci., 37, 634-642, 1985.

Knap, A. H., Michaels, A., Close, A. R., Ducklow, H., and Dickson, A. G.: Protocols for the joint global ocean flux study (JGOFS) core measurements, JGOFS Repr. IOC Man. Guid. No 29 UNESCO 1994, 19, available at: http://epic.awi.de/17559/1/ Kna1996a.pdf (last access: 15 October 2014), 1996.

Kolber, Z. and Falkowski, P. G.: Use of active fluorescence to estimate phytoplankton photosynthesis in situ, Limnol. Oceanogr., 38, 1646-1665, doi:10.4319/lo.1993.38.8.1646, 1993.

Kolber, Z. S., Prášil, O., and Falkowski, P. G.: Measurements of variable chlorophyll fluorescence using fast repetition rate techniques: defining methodology and experimental protocols, Biochim. Biophys. Acta, 1367, 88-106, doi:10.1016/S00052728(98)00135-2, 1998.

Laureau, C., De Paepe, R., Latouche, G., Moreno-Chacón, M., Finazzi, G., Kuntz, M., Cornic, G., and Streb, P.: Plastid terminal oxidase (PTOX) has the potential to act as a safety valve for excess excitation energy in the alpine plant species Ranunculus glacialis L, Plant Cell Environ., 36, 1296-1310, doi:10.1111/pce.12059, 2013.

Lawrenz, E., Silsbe, G., Capuzzo, E., Ylöstalo, P., Forster, R. M., Simis, S. G. H., Prášil, O., Kromkamp, J. C., Hickman, A. E., Moore, C. M., Forget, M.-H., Geider, R. J., and Suggett, D. J.: Predicting the electron requirement for carbon fixation in seas and oceans, PLoS ONE, 8, e58137, doi:10.1371/journal.pone.0058137, 2013.
Laws, E. A.: Photosynthetic quotients, new production and net community production in the open ocean, Deep-Sea Res., 38, 143167, 1991.

Lee, Y. W., Park, M. O., Kim, Y. S., Kim, S. S., and Kang, C. K.: Application of photosynthetic pigment analysis using a HPLC and CHEMTAX program to studies of phytoplankton community composition, J. Korean Soc. Ocean., 16, 117-124, 2011.

MacCaull, W. A. and Platt, T.: Diel variations in the photosynthetic parameters of coastal marine phytoplankton, Limnol. Oceanogr., 22, 723-731, doi:10.4319/lo.1977.22.4.0723, 1977.

Mackey, K. R. M., Paytan, A., Grossman, A. R., and Bailey, S.: A photosynthetic strategy for coping in a high-light, low-nutrient environment, Limnol. Oceanogr., 53, 900-913, doi:10.4319/lo.2008.53.3.0900, 2008.

McDonald, A. E., Ivanov, A. G., Bode, R., Maxwell, D. P., Rodermel, S. R., and Hüner, N. P. A.: Flexibility in photosynthetic electron transport: the physiological role of plastoquinol terminal oxidase (PTOX), Biochim. Biophys. Acta, 1807, 954-967, doi:10.1016/j.bbabio.2010.10.024, 2011.

McKew, B. A., Davey, P., Finch, S. J., Hopkins, J., Lefebvre, S. C. Metodiev, M. V., Oxborough, K., Raines, C. A., Lawson, T., and Geider, R. J.: The trade-off between the light-harvesting and photoprotective functions of fucoxanthin-chlorophyll proteins dominates light acclimation in Emiliania huxleyi (clone CCMP 1516), New Phytol., 200, 74-85, doi:10.1111/nph.12373, 2013.

Milligan, A. J., Halsey, K. H., and Behrenfeld, M. J.: Advancing interpretations of 14C-uptake measurements in the context of phytoplankton physiology and ecology, J. Plankton Res., 37, 692698, doi:10.1093/plankt/fbv051, 2015.

Mitchell, B. G., Kahru, M., Wieland, J., and Stramska, M.: Determination of spectral absorption coefficients of particles, dissolved material and phytoplankton for discrete water samples, Ocean Opt. Protoc. Satell. Ocean Color Sens. Valid. Revis., 3, 231-257, 2002.

Miyake, C. and Asada, K.: The water-water cycle in algae, in: Photosynthesis in Algae, edited by: Larkum, A. W. D., Douglas, S. E., and Raven, J. A., 183-204, Springer, the Netherlands, available at: http://link.springer.com/chapter/10. 1007/978-94-007-1038-2_9 (last access: 10 March 2015), 2003.

Morel, A., Gentili, B., Claustre, H., Babin, M., Bricaud, A., Ras, J., and Tièche, F.: Optical properties of the "clearest" natural waters, Limnol. Oceanogr., 52, 217-229, doi:10.4319/lo.2007.52.1.0217, 2007.

Myers, J.: On the algae: thoughts about physiology and measurements of efficiency, in: Primary Productivity in the Sea, edited by: Falkowski, P. G., 1-16, Springer, New York, US, available at: http://link.springer.com/chapter/10.1007/ 978-1-4684-3890-1_1 (last access: 28 August 2015), 1980.

Nawrocki, W. J., Tourasse, N. J., Taly, A., Rappaport, F., and Wollman, F.-A.: The plastid terminal oxidase: its elusive function points to multiple contributions to plastid physiology, Annu. Rev. Plant Biol., 66, 49-74, doi:10.1146/annurev-arplant-043014114744,2015

Niyogi, K. K.: Safety valves for photosynthesis, Curr. Opin. Plant Biol., 3, 455-460, doi:10.1016/S1369-5266(00)00113-8, 2000.

Öquist, G., Chow, W. S., and Anderson, J. M.: Photoinhibition of photosynthesis represents a mechanism for the longterm regulation of photosystem II, Planta, 186, 450-460, doi:10.1007/BF00195327, 1992. 
Ottesen, E. A., Young, C. R., Gifford, S. M., Eppley, J. M., Marin, R., Schuster, S. C., Scholin, C. A., and DeLong, E. F.: Multispecies diel transcriptional oscillations in open ocean heterotrophic bacterial assemblages, Science, 345, 207-212, doi:10.1126/science.1252476, 2014.

Oxborough, K. and Baker, N. R.: Resolving chlorophyll $a$ fluorescence images of photosynthetic efficiency into photochemical and non-photochemical components - calculation of qP and $F_{\mathrm{v}}^{\prime} / F_{\mathrm{m}}^{\prime}$; without measuring $F^{\prime}{ }_{\mathrm{o}}$, Photosynth. Res., 54, 135-142, doi:10.1023/A:1005936823310, 1997.

Oxborough, K., Moore, C. M., Suggett, D. J., Lawson, T., Chan, H. G., and Geider, R. J.: Direct estimation of functional PSII reaction center concentration and PSII electron flux on a volume basis: a new approach to the analysis of Fast Repetition Rate fluorometry (FRRf) data, Limnol Ocean. Methods, 10, 142-154, 2012.

Pei, S. and Laws, E. A.: Does the ${ }^{14} \mathrm{C}$ method estimate net photosynthesis? Implications from batch and continuous culture studies of marine phytoplankton, Deep-Sea Res., 82, 1-9, doi:10.1016/j.dsr.2013.07.011, 2013.

Pinckney, J. L.: HPLC Method - Technical - Estuarine Ecology, available at: https://sites.google.com/site/jaypinckney/ home/protocols-reports/hplc-method-technical (last access: 1 October 2015), 2013.

Pope, R. M. and Fry, E. S.: Absorption spectrum (380-700 nm) of pure water. II. Integrating cavity measurements, Appl. Optics, 36, 8710, doi:10.1364/AO.36.008710, 1997.

Prasil, O., Kolber, Z., Berry, J. A., and Falkowski, P. G.: Cyclic electron flow around Photosystem II in vivo, Photosynth. Res., 48, 395-410, doi:10.1007/BF00029472, 1996.

Prézelin, B. B.: Diel periodicity in phytoplankton productivity, Hydrobiologia, 238, 1-35, 1992.

Raateoja, M. P.: Fast repetition rate fluorometry (FRRF) measuring phytoplankton productivity: a case study at the entrance to the Gulf of Finland, Baltic Sea, Boreal Environ. Res., 9, 263-276, 2004.

Raven, J. A., Evans, M. C. W., and Korb, R. E.: The role of trace metals in photosynthetic electron transport in $\mathrm{O}_{2}$-evolving organisms, Photosynth. Res., 60, 111-150, doi:10.1023/A:1006282714942, 1999.

Ribalet, F., Swalwell, J., Clayton, S., Jiménez, V., Sudek, S., Lin, Y., Johnson, Z. I., Worden, A. Z., and Armbrust, E. V.: Light-driven synchrony of Prochlorococcus growth and mortality in the subtropical Pacific gyre, Proc. Natl. Acad. Sci. USA, 201424279, doi:10.1073/pnas.1424279112, 2015.

Roháček, K.: Chlorophyll fluorescence parameters: the definitions, photosynthetic meaning, and mutual relationships, Photosynthetica, 40, 13-29, doi:10.1023/A:1020125719386, 2002.

Röttgers, R. and Gehnke, S.: Measurement of light absorption by aquatic particles: improvement of the quantitative filter technique by use of an integrating sphere approach, Appl. Opt., 51, 13361351, 2012.

Schrader, P. S., Milligan, A. J., and Behrenfeld, M. J.: Surplus photosynthetic antennae complexes underlie diagnostics of iron limitation in a cyanobacterium, PLoS ONE, 6, e18753, doi:10.1371/journal.pone.0018753, 2011.

Schreiber, U.: Pulse-amplitude-modulation (PAM) fluorometry and saturation pulse method: an overview, Chlorophyll Fluoresc., 19, 279-319, 2004.
Schuback, N., Schallenberg, C., Duckham, C., Maldonado, M. T., and Tortell, P. D.: Interacting effects of light and iron availability on the coupling of photosynthetic electron transport and $\mathrm{CO}_{2}$ assimilation in marine phytoplankton, PLoS ONE, 10, e0133235, doi:10.1371/journal.pone.0133235, 2015.

Silsbe, G.: Phytotools: Phytoplankton Production Tools, An R package available on CRAN: https://cran.r-project.org/web/packages/ phytotools/index.html, 2015.

Streb, P., Josse, E.-M., Gallouët, E., Baptist, F., Kuntz, M., and Cornic, G.: Evidence for alternative electron sinks to photosynthetic carbon assimilation in the high mountain plant species Ranunculus glacialis, Plant Cell Environ., 28, 11231135, doi:10.1111/j.1365-3040.2005.01350.x, 2005.

Stross, R. G., Chisholm, S. W., and Downing, T. A.: Causes of daily rhythms in photosynthetic rates of phytoplankton, Biol. Bull., 145, 200-209, doi:10.2307/1540359, 1973.

Suggett, D., Kraay, G., Holligan, P., Davey, M., Aiken, J., and Geider, R.: Assessment of photosynthesis in a spring cyanobacterial bloom by use of a fast repetition rate fluorometer, Limnol. Oceanogr., 46, 802-810, 2001.

Suggett, D. J., Maberly, S. C., and Geider, R. J.: Gross photosynthesis and lake community metabolism during the spring phytoplankton bloom, Limnol. Oceanogr., 51, 2064-2076, 2006.

Suggett, D. J., Moore, C. M., Hickman, A. E., and Geider, R. J.: Interpretation of fast repetition rate (FRR) fluorescence: signatures of phytoplankton community structure versus physiological state, Mar. Ecol.-Prog. Ser., 376, 1-19, 2009.

Suggett, D. J., Moore, C. M., and Geider, R. J.: Estimating aquatic productivity from active fluorescence measurements, in: Chlorophyll $a$ Fluorescence in Aquatic Sciences: Methods and Applications, edited by: Suggett D. J., Prasil O., and Borowitzka M. A., 103-127, Springer, the Netherlands, 2010.

Suzuki, K., Liu, H., Saino, T., Obata, H., Takano, M., Okamura, K., Sohrin, Y., and Fujishima, Y.: East-west gradients in the photosynthetic potential of phytoplankton and iron concentration in the subarctic Pacific Ocean during early summer, Limnol. Oceanogr., 47, 1581-1594, 2002.

Suzuki, L. and Johnson, C. H.: Algae know the time of day: circadian and photoperiodic programs, J. Phycol., 37, 933-942, doi:10.1046/j.1529-8817.2001.01094.x, 2001.

Taylor, R. L., Semeniuk, D. M., Payne, C. D., Zhou, J., Tremblay, J.É., Cullen, J. T., and Maldonado, M. T.: Colimitation by light, nitrate, and iron in the Beaufort Sea in late summer, J. Geophys. Res., 118, 3260-3277, doi:10.1002/jgrc.20244, 2013.

Vass, I.: Role of charge recombination processes in photodamage and photoprotection of the photosystem II complex, Physiol. Plant., 142, 6-16, doi:10.1111/j.1399-3054.2011.01454.x, 2011.

Vassiliev, I. R., Kolber, Z., Wyman, K. D., Mauzerall, D., Shukla, V. K., and Falkowski, P. G.: Effects of iron limitation on photosystem II composition and light utilization in Dunaliella tertiolecta, Plant Physiol., 109, 963-972, doi:10.1104/pp.109.3.963, 1995.

Webb, W. L., Newton, M., and Starr, D.: Carbon dioxide exchange of Alnus rubra. A mathematical model, Oecologia, 17, 281-291, 1974.

Welschmeyer, N. A.: Fluorometric analysis of chlorophyll $a$ in the presence of chlorophyll $b$ and pheopigments, Limnol. Oceanogr., 39, 1985-1992, 1994. 
Williams, P. J. le B., Thomas, D. N., and Reynolds, C. S.: Phytoplankton Productivity: Carbon Assimilation in Marine and Freshwater Ecosystems, John Wiley and Sons, New York, 2008.

Yruela, I.: Transition metals in plant photosynthesis, Met. Integr. Biometal Sci., 5, 1090-1109, doi:10.1039/c3mt00086a, 2013.

Zehr, J. P. and Kudela, R. M.: Photosynthesis in the Open Ocean, Science, 326, 945-946, doi:10.1126/science.1181277, 2009.
Zhao, Y. and Quigg, A.: Study of photosynthetic productivity in the Northern Gulf of Mexico: importance of diel cycles and light penetration, Cont. Shelf Res., 102, 33-46, doi:10.1016/j.csr.2015.04.014, 2015. 